\title{
WestVirginiaUniversity
}

THE RESEARCH REPOSITORY @ WVU

$6-2020$

\section{Professional Sporting Events Increase Seasonal Influenza Mortality in US Cities}

Alexander Cardazzi

Brad Humphreys

Jane E. Ruseski

Brian P. Soebbing

Nicholas Watanabe

Follow this and additional works at: https://researchrepository.wvu.edu/econ_working-papers

Part of the Health Economics Commons, Influenza Humans Commons, Sports Management Commons, and the Sports Studies Commons 


\title{
Professional Sporting Events Increase Seasonal Influenza Mortality in US Cities
}

\author{
Alexander Cardazzi \\ West Virginia University \\ Brad R. Humphreys* \\ Jane E. Ruseski \\ West Virginia University \\ West Virginia University \\ Brian P. Soebbing \\ University of Alberta \\ Nicholas Watanabe \\ University of South Carolina
}

June 16, 2020

\begin{abstract}
The COVID-19 pandemic shut down sporting events worldwide. Local policy makers and league officials face important decisions about restarting play, especially in professional leagues that draw large numbers of spectators to games. We analyze the impact of professional sporting events on local seasonal influenza mortality to develop evidence that will help inform sports league reopening policy decisions. Results from a difference-in-differences model applied to data from a sample of US cities that gained new professional sports teams over the period 1962-2016 show that the presence of games in these cities increased local influenza mortality by between $4 \%$ and $24 \%$, depending on sport, relative to cities with no professional sports teams and relative to mortality in those cities before a new team arrived. Influenza mortality fell in cities with teams in some years when work stoppages occurred in sports leagues. Sports league reopening policies should take into account the role played by sporting events in increasing local seasonal flu mortality.
\end{abstract}

Key words: influenza mortality; sporting events; health policy

\footnotetext{
${ }^{*}$ Corresponding author. John Chambers College of Business \& Economics, Department of Economics. 1601 University Ave., PO Box 6025, Morgantown, WV 26506-6025, USA; Email: brhumphreys@mail.wvu.edu. We thank participants in the ROSES seminar hosted by the University of Reading, UK, for useful comments and suggestions.
} 


\section{Introduction}

On March 11, 2020, the National Basketball Association (NBA) suspended the remainder of the 2019-2020 season due to fears of transmission of the highly contagious and deadly COVID-19 virus after a player tested positive for the virus prior to the start of a game (ESPN News Services, 2020). On the same day, the National Collegiate Athletic Association (NCAA) announced that the Men's and Women's basketball "March Madness" tournaments would be played without fans due to the threat of the coronavirus. Hours later, the NCAA revised its plans and cancelled both tournaments. In the hours that followed, all college basketball conferences suspended play.

Soon thereafter, other professional sports leagues around the world, including the National Hockey League (NHL), and European football leagues, suspended play. Major League Baseball (MLB) postponed the start of the 2020 season. Universities around the country cancelled all spring sports competitions. In a matter of weeks, new policies designed to mitigate the spread of the COVID-19 virus disrupted the worldwide sports scene.

After two months of cancelled matches, the German Bundesliga resumed play in stadiums without fans on May 15, 2020. By mid-June 2020, the NBA and NHL set targeted dates and plans to resume their suspended season. Both MLB and NFL are evaluating options and timetables for starting their season. College football players are returning to campus for preparation for the upcoming season in the fall. Governors of many states are expressing interest in bringing sports back with some even expressing having some fans in the stadiums to watch live sporting events. Universities are evaluating the prospects of bringing students back to campus for the upcoming schools year. Several critically important questions immediately emerge at the intersection of sport and public health policy when contemplating bringing sports back.

First, will there be a "second wave" of the coronavirus outbreak as athletes unavoidably come into contact with each other during competition, and fans begin to emerge from their homes to cheer their teams on in public places? Second, will fans respect and follow public 
health policies for social distancing and proper use of personal protective equipment when attending or watching games?

This present study sheds some light on these questions by evaluating the impact of the entry of new professional MLB, NBA, NFL, or NHL teams into US cities on past seasonal influenza mortality rates. Since seasonal influenza and COVID-19 share similar transmission mechanisms, the impact of sporting events on seasonal influenza mortality rates can help government and sports league policy makers determine when and how to safely resume sporting events.

Our paper contributes to a small, growing literature on the impact of economic factors on virus transmission and mortality. Adda (2016) investigated the impact of public transit strikes, high speed rail link openings, and school closures in France on the transmission of three viruses (influenza, gastroenteritis, and chickenpox) and reported evidence that these exogenous shocks affected the transmission rates of all three viruses. Stoecker et al. (2016), in a closely related paper, investigated the relationship between postseason success by local NFL football teams and influenza mortality in the cities home to these teams. Stoecker et al. (2016) exploited exogenous variation in NFL team postseason success in January and February to analyze the impact of attendance at games, informal local gatherings to watch games, and travel to other areas to watch games on flu mortality. Based on a comparison of flu mortality in 278 counties in Metropolitan Statistical Areas (MSAs) home to NFL teams over the period 1974 to 2009, their research found that NFL team appearances in the Super Bowl caused an $18 \%$ increase in flu mortality in the local population over age 65 .

The entry of a professional sports team into a city represents a reasonable proxy for the resumption of sports following the recent COVID-19 shutdowns. A new team entering a city essentially turns on a switch possibly increasing flu transmission among fans attending or gathering to watch games in the city. This event resembles current local conditions in cities when sports teams resume play and the economy emerges from the coronavirus pandemic shut down. We exploit geographic variation in the entry of new professional sports teams 
into cities, and temporal variation in the start of play in MLB's, NBA's, NFL's, and NHL's 1962 through 2016 seasons as proxies for changes in factors affecting influenza transmission through opportunities to attend or watch sporting events.

We posit these changes are plausibly exogenous to unobservable factors affecting influenza transmission and mortality in cities with professional sports teams. The results show cities acquiring one new professional sports team experienced $4 \%$ to $24 \%$ increases in local influenza mortality across all age groups compared to cities without professional sports teams, suggesting that sports-related changes in social distancing patterns represent important influenza transmission mechanisms. These results are in line with Stoecker et al. (2016) who estimated an $18 \%$ increase in flu mortality among the local population age 65 or older in MSAs that sent an NFL team to the Super Bowl. In addition, local flu mortality fell in some years when work stoppages occurred in sports leagues, further buttressing the evidence that games played by professional sports teams make substantial contributions to local seasonal flu mortality.

This paper contributes to the economic policy literature by establishing a general impact of sporting events on local flu mortality caused by regular season and postseason games in professional sports leagues, extending the results for postseason success by NFL teams in Stoecker et al. (2016). Local and league policy makers currently face the choice of playing or not playing games, not the choice of fielding a successful or unsuccessful local team. The identification in this paper, the commencement of play by a new team in a city, provides policy makers with additional information about the impact of sporting events on local flu mortality beyond the success-based identification in Stoecker et al. (2016). The temporal identification includes games played before and throughout the start of the annual flu season, extending the effective treatment period beyond the late December to early February peak flu death period analyzed by Stoecker et al. (2016). This paper also analyzes the impact of strikes on virus transmission/mortality extending the work by Adda (2016) to a novel setting with frequent, important work stoppages. 


\section{Context}

Influenza is an infectious disease transmitted through airborne particles from an infected individual, generated by coughing, sneezing, or potentially talking or shouting, coming in contact with an uninfected individual. Another means of transmission occurs when an infected individual expels virus onto surfaces like railings, seats, doorknobs, and sink fixtures and an uninfected person touches this surface, gets flu virus on her hands, and then touches her face and contracts the virus.

Uncontained influenza epidemics and pandemics impose sizeable economic costs, in terms of loss of life, health care costs, unmet health care needs, productivity losses, and reductions in human capital, generating large incentives to control and prevent their spread. While vaccination and herd immunity likely represent the most effective preventative strategies, they are not viable options in the short-run due to the time required to develop and produce an effective vaccine and to achieve an effective level of herd immunity. COVID-19 represents a new and especially virulent flu strain with no existing vaccine or herd immunity, amplifying the importance of preventative policies.

Feasible short-run strategies for reducing transmission include altering social interaction patterns through social distancing and limiting contact with vulnerable populations. Since the reporting of the initial novel coronavirus outbreak in China in December 2019, social distancing through "stay at home" directives, self-imposed and mandated isolation, and shutting down non-essential businesses has been the prevention strategy of the vast majority of states in the United States and countries around the world.

However, weighing the economic costs of these "stay at home" and lock down directives against the economic costs of the virus is an important and emotionally charged consideration for government and health officials. After two or more months of limited economic activity that rapidly threw many large and growing economies into recession, the pressure to restart economic activity, including the resumption of sporting events, through relaxation of COVID19 restrictions is high. 
We investigate the impact of the relaxation of policies prohibiting large gatherings on local health outcomes through the lens of professional sporting events, in particular games played in four major professional sports leagues (MLB, NBA, NFL, and NHL) in the United States. We posit that professional sports games increase transmission of influenza, negatively impacting local health outcomes compared to an environment where no games occur. Increased transmission eventually reaches vulnerable populations that never attended or watched these game, increasing flu mortality. The relationship between large numbers of spectators attending sporting events and flu transmission relates to social distancing because attending games, or gathering in confined areas like bars, restaurants, or homes, to watch games, significantly reduces social distance. Sporting events place large numbers of people in close quarters. These fans touch many surfaces and engage in substantial talking, yelling, face touching, and person-to-person contact like "high fives." People gathering in homes or public spaces to watch sporting events on media creates similar conditions. Maintaining the current recommended social distancing guidelines of small gatherings with at least 6 feet of space between individuals is challenging, if not impossible, in a crowded sports venue or bar.

Recent research exploits plausibly exogenous events to advance understanding of the role of social distancing and economic activity in the transmission of viruses. One strand of literature examines the impact of large sports-related gatherings on influenza infections and mortality including participants in the 2002 Winter Olympics (Gundlapalli et al., 2006), spectators at the 2006 FIFA World Cup (Williams et al., 2009), and residents of cities home to NFL teams playing in the Super Bowl (Stoecker et al., 2016). A related literature develops evidence linking negative cardiovascular and infant health outcomes to sporting events (Kloner et al., 2009, 2011; Leeka et al., 2010; Duncan et al., 2017).

A second strand of literature explores the impact of large non-sports related gatherings and events on the spread of infectious disease. These gatherings include music festivals (Gutiérrez et al., 2009; Botelho-Nevers et al., 2010), the annual Hajj pilgrimage to Mecca (Balkhy et al., 2004; Al-Tawfiq et al., 2016), college spring break Mangrum and Niekamp 
(2020), and school closures and transit strikes in France (Cauchemez et al., 2008; Adda, 2016). ${ }^{1}$ American Academy of Pediatrics (2006) and Adda (2016) analyzed the effect of travel-related shocks, in the form of the $9 / 11$ related air travel shut down and transit strikes respectively, on infectious diseases. Stoecker et al. (2016) and Adda (2016) are the two most closely related papers in the literature to this study.

Stoecker et al. (2016) exploit temporal and geographic variation in annual NFL team success as a proxy for changes in social distancing patterns through either increased fan social interaction or travel. They compare flu mortality for the population over age 65 in counties in MSAs with NFL teams that played in the Super Bowl to counties home to NFL teams that did not reach the Super Bowl in a given season. They find that counties in MSAs with NFL teams that played in the Super Bowl caused an 18 percent increase in influenza deaths for the population over age 65 in those counties. Stoecker et al. (2016) posit that increases in large gatherings in MSAs home to these successful teams lead to increases in frequency of human contact and an increased probability of local transmission.

Interestingly, Stoecker et al. (2016) report no evidence of increases in flu mortality in cities that hosted the Super Bowl, suggesting that changes in travel patterns bringing large numbers of spectators to the host city play a small role in the process. This result does not completely rule out changes in travel patterns as a mechanism for transmission. It is possible that the mechanism works in the opposite direction: fans who travel to the host city for the Super Bowl become infected there and bring the virus back home with them resulting in an increase in infections and deaths in the sending city.

This explanation is consistent with anecdotal evidence for the quick and deadly spread of the coronavirus in Bergamo, Italy, in February 2020. Health officials speculate the large number of fans (about 40,000) who traveled to Milan to attend a football match between the team in Bergamo and a Spanish team from Valencia contracted the virus in or en route to and from Milan, brought it back to Bergamo and subsequently infected many local elderly

\footnotetext{
${ }^{1}$ See Gautret and Steffen (2016) for a systematic review of studies about communicable diseases as health risks at mass gatherings.
} 
residents who did not attend the match (Giuffrida, 2020).

Adda (2016) uses high frequency data from France to evaluate the impact of plausibly exogenous events (school closures, public transportation strikes, and expansion of transportation networks in the form of new high speed train lines) on the transmission of infectious diseases, including influenza, for different age groups. Adda (2016) finds a substantial impact of these events on the incidence of viral diseases in the expected direction; school closures and public transportation strikes significantly reduced disease prevalence while expansion of train lines increased viral spread.

The present research contributes to this literature in a number of important ways. Using novel data from the Centers for Disease Control and Prevention (CDC) containing information on weekly influenza and pneumonia deaths in 122 US cities over the period 1962 to 2016, we analyze variation in weekly flu mortality in cities gaining new professional sports teams over the sample period relative to variation in cities with no professional sports teams at any point over the sample period. We exploit substantial geographical and temporal variation in the arrival of a new professional sports team to a city to identify the effect of sports-related local gatherings on local flu mortality.

Leagues and local policy makers suspended games due to concerns and uncertainties surrounding the safety and health of fans, coaches, and players due to the coronovirus pandemic. In particular, concerns about the role of large gatherings by fans increasing virus transmission. Our empirical analysis generates evidence about the impact of restarting games, based on past health outcomes in cities adding new teams in four major professional sports leagues over the last half a century. Analyzing the impact of the commencement of play in cities represents a closer analog to the decision facing policy makers today to restart league play compared to the NFL team success-based approach used by Stoecker et al. (2016) and extends the analysis of the impact of rail-based transmission mechanisms used by Adda (2016) to a novel setting. 


\section{Empirical Analysis}

\subsection{Empirical Method}

We employ a differences-in-differences (DiD) approach to identify the impact of welcoming a new professional sports team into a city on local health outcomes as reflected in influenza mortality. We posit professional sporting events increase the transmission of the flu virus among residents in a city, either by putting attendees in close proximity at games, or putting fans in close proximity in social gatherings organized around watching or listening to games in homes, bars, or restaurants. The sporting events effectively alter social distancing patterns in a way that increases the probability of becoming infected with flu virus. This increased transmission eventually reaches vulnerable populations who did not attend games or gather to watch them on television.

We focus on the impact of a new professional sports team entering a city in each of the four major leagues (NBA, NFL, NHL, and MLB) on local health outcomes. The DiD model explaining observed weekly variation in flu mortality takes the form:

$$
D_{c t}=\delta I\left(G_{c, w_{s}, w_{e}, c}^{s}\right)+\gamma C_{c t}+\zeta_{c}+\tau_{t}+\mu_{m}+\psi_{y}+\epsilon_{t i c}
$$

where the dependent variable $D_{c t}$ is influenza mortality, measured as reported deaths from influenza or pneumonia per 100,000 population in city $c$ in time period $t$. Let $I\left(G_{w_{s}, w_{e}, c}^{s}\right)$ be an indicator function that is equal to 1 if games were played by team $i$ in sport $s=$ $N F L, N B A, N H L, M L B$ in city $c$ between week $w_{s}$ and week $w_{e} . C_{c t}$ is a vector of observable time varying city specific variables like population, temperature, precipitation, and other time varying city specific factors related to flu mortality. We include the average temperature and inches of precipitation during flu season in $C_{c t}$ to control of the influence of environmental factors on flu transmission (Soebiyanto et al., 2010).

$\zeta_{c}$ is a vector of city-specific fixed effects to control for unobservable time invariant cityspecific heterogeneity in factors affecting flu mortality. $\tau_{t}$ is a vector of week-in-sample fixed 
effects and $\mu_{m}$ a vector of month-of-the-year specific effects capturing unobservable timerelated heterogeneity affecting flu mortality in cities. Such factors include hours of daylight, school calendar effects, holidays, and other time varying factors. $\psi_{y}$ a vector of flu season specific effects to capture heterogeneity in specific flu seasons. This vector includes indicator variables identifying the specific flu strain most prevalent in each flu season. The mean zero, possibly heteroscedastic error term $\epsilon_{c s t}$ captures other random unobservable factors affecting flu mortality in cities over time.

$\delta$ is a vector of parameters of interest that reflects the impact of games played on flu mortality in each city. Two assumptions must hold for estimates of $\delta$ using the DiD approach to deliver plausibly causal estimates of the average treatment effect of sporting events on flu mortality. First, the treatment must be uncorrelated with time varying city specific unobservable factors affecting the outcome variable. Second, the time path of the outcome variable in the treated and control groups must be the same, except for the impact of the treatment on the outcome variable in the treated group, called the parallel trends assumption. Although neither assumption can be tested directly, most DiD research develops empirical evidence that these assumptions hold in the data. We first discuss data sources and details in the next section before turning to a discussion of identification in the following section.

\subsection{Data Sources}

We collected and combined data from a number of sources. Data on flu mortality come from the US Centers for Disease Control and Prevention (CDC) 122 Cities Mortality Reporting System (CMRS). We augment this city level flu mortality data with city population data from the United State Census and the American Community Survey (ACS) maintained by the US Census Bureau to estimate flu mortality rates. Information related to the professional sports teams like opening day for a new team in a city, season schedules in each sports league, and work stoppages in sports leagues come from team and sport web sites and media sources. Data on environmental factors that affect flu transmission, in particular variables reflecting 
temperature and precipitation in cities, come from the National Oceanic and Atmospheric Administration (NOAA). Information on the virulence of different flu strains circulating in each flu season in various seasons comes from the epidemiology literature on flu transmission.

\subsubsection{Flu Mortality Data}

Seasonal influenza mortality represents the key local health outcome variable analyzed in this paper. We obtained the weekly influenza deaths in 122 US cities over the period 1962 to 2016 from the CDC's CMRS. These data appear in Table III published regularly in the CDC's Morbidity and Mortality Weekly Report (MMWR). Public health officials in 122 US cities voluntarily report detailed mortality data to the CDC each week. The Appendix contains a list of cities in the sample. Most of the 122 cities have a population of more than 100,000 people. CMRS death counts reflect where deaths occurred, not where the deceased resided, and also reflect the week in which the death certificate was filed. These data do not include fetal deaths. The total reported deaths in each city-week cell includes persons with unknown age. Previous research in the epidemiology and medicine literatures utilized these publicly available data (Brownstein et al., 2005; Viboud et al., 2010; Krieger et al., 2015).

The CMRS data contain temporal identifiers for the calendar year and the annual influenza season or year. Unlike the calendar year, a "flu year" begins in July and ends in June to reflect the typical cyclical variation in flu incidence and mortality, which typically remains low throughout the summer and increases during the winter. The CMRS data contain information on deaths, including influenza and pneumonia deaths, for seven day periods ending on Thursday throughout the year. We define the first week of the flu year as the first full week of July for which the CMRS reports death data and the last week of the flu year as the last week of June, which can also include observations from the first three days of July. The CDC does not define the flu season as any specific part of the flu year, but the flu season is generally understood to run from early October until late May in each flu year. 


\subsubsection{Other Data}

The 122 cites appearing in the CMRS data represent political jurisdictions, not MSAs or other urban areas identified in the Census Bureau's geographical classification system. The cities in the CMRS correspond to places ("a concentration of population ... A place either is legally incorporated under the laws of its respective State, or a statistical equivalent that the Census Bureau treats as a census designated place (CDP).") in the Census Bureau's geographical classification system. Since the CMRS data do not contain information on city population, city-level population estimates must be obtained elsewhere. The decennial census contains estimates for population in Census places. Crosswalk files linking places to counties also exist for the 1990, 2000, and 2010 Censuses as well as the American Community Survey (ACS). We obtained Census place/CMRS city level population data from the 1960, 1970, 1980, 1990, 2000 and 2010 Census. Following Adda (2016), we linearly interpolate annual population for each city in the inter-censal years. We obtained estimates of annual population for places for the 2011-2016 period from the ACS, maintained by the US Census Bureau.

We exploit temporal variation in both the arrival date of new NBA, NFL, NHL, and MLB teams in cities and the start of play in sports leagues to analyze observed variation in influenza mortality. We hand collected data on the timing of new franchise arrival in cities and work stoppages from team web sites and media reports. Data on the date and teams involved in each NBA, NFL, NHL, and MLB game played over the sample, including the data of the first game played in a city gaining a new team, come from the standard comprehensive sports data web sites. ${ }^{2}$

The environmental data come from the National Oceanic and Atmospheric Administration (NOAA), and include average monthly temperature and total monthly precipitation by county. These data are then matched to the main dataset and used to control for conditions

\footnotetext{
${ }^{2}$ https://www.basketball-reference.com/; https://www.pro-football-reference.com/; https: //www.hockey-reference.com/; https://www.baseball-reference.com/.
} 
that may facilitate flu transmission. For example, cold weather and plenty of precipitation may keep people inside, decreasing the potential for spread amongst the population. On the other hand, these factors may increase transmission by the same mechanism of keeping people inside and thus closer together, relative to a warm, sunny day at a park. Temperature and humidity also affect the virulence of flu strains. Flu viruses have a more difficult time living in geographic areas with higher temperatures and humidity. Thus, controlling for environmental factors such as these is important.

We include indicator variables for the four common, virulent influenza strains that circulated in the US over the sample period: H3N2, H2N2, H1N1 and B. The data identifying predominant viral strains circulating in each flu season and the presence of flu pandemics was gathered from tables in Greene et al. (2006) and Simonsen et al. (1998), as well as from the Centers for Disease Control and Prevention (2020) US Outpatient Influenza-like Illness Surveillance Network (ILINet) maintained by the CDC.

Figure A3 in the Appendix shows four common influenza strains and their dominance in each flu year in the sample. H3N2 and H1N1 are by far the most prevalent flu strains circulating during the sample period. H2N2 was dominant in the first few years of the sample (1962-1966) but then died out. The B flu strain only circulated in the early 2000's. In our empirical analysis, the B flu strain is the omitted category because it was rarely prevalent over the sample period.

\subsection{Sample Determination}

The cities participate voluntarily in the CMRS; no sampling procedure determines which cities appear in the data. Stoecker et al. (2016) use comprehensive county level flu death mortality data in their analysis and define treated counties as any county in an MSA with an NFL team. The use of data from multiple sports and a different data source preclude that approach in this setting. Table A1 in the Appendix lists all 122 cities in the CMRS data. Each of the cities in the CMRS data have a unique set of circumstances in terms 
of existence, entry and exit of professional sports teams, location of stadiums and arenas, and location. This requires some adjustments to the cities included in the sample. We decide whether to include and aggregate the flu mortality data or to exclude the cities from the sample on a case-by-case basis. Table A2 in the Appendix summarizes decisions and rationales concerning inclusion or exclusion of cities in the sample.

Our objective is to define a sample of cities, treatment periods, and treatment and control groups from this sample that will best proxy the impact cities can expect when local professional sports teams resume play. We exclude cities that did not report weekly flu deaths for the entire 1962-2016 sample period (Boise, Fort Worth, Lansing, MI, Las Vegas, Lexington, KY, Philadelphia, Pittsburgh, and Santa Cruz) as well as New Orleans and Baton Rouge, LA who did not report weekly flu deaths for multiple years during the sample period.

Adda (2016) identified important patterns in spatial transmission of several viruses, including seasonal influenza, in France due to inter-regional travel. Including cities located in close proximity would require spatial modelling like in Adda (2016). As an alternative, we drop cities located in the same MSA from the sample. These include cities in the New York-Newark-Jersey City, NY-NJ-PA MSA (the five boroughs of New York City, Yonkers, Elizabeth, Jersey City, Newark, and Paterson New Jersey), cities in the Los Angeles MSA (Los Angeles, Long Beach, Glendale, and Pasadena), cities in the San Francisco-Oakland-Berkeley MSA (San Francisco and Berkeley) and Camden, New Jersey which is part of the Philadelphia MSA.

In addition to concerns about spatial transmission of the flu virus, each of these cities pose problems for identification of the role played by professional sporting events in flu transmission. The five boroughs of New York City, and the contiguous city of Yonkers, contain extensive public transportation networks that makes commuting and recreational travel among these areas, as well as to the neighboring sample cities in northern New Jersey very easy. The two New York City based NFL teams played their home games in Rutherford, New Jersey, several miles outside the city, for much of the sample period. One of the NHL 
teams in the area, the Islanders, played games primarily in Nassau, on Long Island. One of the area NBA teams, the Nets, moved several times within the area during the sample period including several seasons in Newark, NJ. These factors impact identification using DiD in complex ways and require extensive spatial modelling. One borough, Staten Island, contains no professional sports teams. Also, a majority of the professional sports teams in the area played games throughout the entire sample period, making their impact on flu transmission difficult to assess relative to city or area fixed effects.

The Los Angeles area was home to one MLB team throughout the sample period, and a second MLB team, the Angels, played in nearby Anaheim throughout the sample period. A new NHL team also moved into Anaheim during the sample period. The area lacked an NFL team for the entire post 1996 sample period and had multiple teams in Los Angeles and Anaheim prior to 1996. Information about fan travel within the MSA to different sports venues does not exist. Also, Los Angeles contains the only arena home to multiple NBA teams (the Lakers and Clippers) and an NHL team. These factors make identification difficult.

Two professional sports teams the 49ers (NFL) and the Giants (MLB), in the San Francisco-Oakland-Berkeley MSA played games at Candlestick Park, located outside the City of San Francisco over much of the sample period. The NBA team played in Oakland for much of the sample period. Another MLB team, the Athletics, played in Oakland over the entire sample period. Berkeley, a relatively small city, can be easily reached from San Francisco by public transportation and contains a large research university. These factors make identification difficult.

We drop Chicago from the sample. Almost no variation in professional sports teams exists in Chicago over the sample period. The NBA's Chicago Zephyrs played in the city in the 1962/63 season at the beginning of the sample before moving to Baltimore in summer 1963. The Bulls arrived in the city in 1966. This complicates any identification of an NBA impact in Chicago because of the lack of a pre-treatment period. The MLB, NFL and NHL 
teams in Chicago played there throughout the sample period.

On the other hand, we aggregate city level flu mortality data in three areas: Tampa and Saint Petersburg in Florida, Minneapolis and Saint Paul, in Minnesota, and Kansas City Kansas and Kansas City, Missouri. These cities are all contiguous and of similar size. Professional sports facilities exist in all of these cities, and their separation in the CMRS data represents jurisdictional features that seem unlikely to influence flu transmission across the cities. We assume these separate political entities can be treated as homogenous areas in terms of flu transmission and mortality. The empirical results are not sensitive to the inclusion of these aggregate two-city flu mortality data.

We can further take advantage of the differential coincidence of the leagues' regular and post seasons with the flu season to identify potential variation in the impact of professional sporting events on flu transmission and, ultimately, flu deaths. For example, we might expect flu deaths associated with the arrival of a new NBA or NHL team to be different from the arrival of an NFL team whose season runs before and during the flu season. The impact of new MLB teams should differ from the other leagues since they generally occur outside flu season. Any such differences revealed from our empirical analysis will be informative for what to expect as professional sports leagues around the world resume play at different points in the "flu year".

Another empirical issue related to sample determination involves the time lag between $\mathrm{flu}$ transmission at games and flu deaths. Adda (2016) faces a similar issue in modeling the lag between school closures and public transportation strikes and $\mathrm{flu}$ infections and handles it by imposing a lag structure based on typical incubation periods for the different viruses considered. In our case, the end of the treatment period, $w_{e}$ in the indicator function $I\left(G_{w_{s}, w_{e}, c}^{s}\right)$ in equation (1) could be defined in several ways. It could be set at a period some weeks following the last game played in a city in the flu year, at the end of the current flu season, or the end of the sample period. We choose to define $w_{e}$ as the end of the sample period. This definition assumes the effect of sporting events on flu transmission is permanent, 
lasting as long as the team plays games in the city. We think this approach is preferable to a distributed lag specification because it avoids the restrictive assumptions about the time between flu transmission and deaths associated with games. Under this end-of-treatment period definition, the parameter estimate $\hat{\delta}$ represents the average effect of the presence of games being played in a city on weekly flu deaths over the entire period following a team's arrival in the city.

Stoecker et al. (2016) aggregate flu death data to the "season" level which seems reasonable since their treatment approach applies to counties in MSAs with NFL teams that ultimately played in the championship game, the Super Bowl. The transmission increase generated by postseason appearances occurs after the flu season is well underway in those counties. Our treatment concept differs from Stoecker et al. (2016) in the sense that we explore what might happen to local flu mortality when the "game on" switch is flipped in sports leagues. This question argues for using higher frequency weekly data, rather than lower frequency monthly or annual data, to detect any effect of the start of play on flu mortality. As a robustness check, we estimate DiD models using annual data like Stoecker et al. (2016) and obtain results similar to those using weekly data.

\subsection{Identification}

The DiD approach requires the treatment to be uncorrelated with unobservable time varying city specific factors that affect the outcome variable, here flu mortality, and the pre-treatment trends in the outcome variables in the treated and control cities to be similar. The present study exploits changes in the number of games played in a city across flu seasons. In this setting, the treatment occurs on an extensive and intensive margin. The extensive margin applies to cities that acquire a new team, moving from no games played in that city to some positive number of games played. The intensive margin applies to variation in the number of games played per time period in cities that gain teams in a sport, commonly called variable treatment intensity. We argue both are uncorrelated with unobservable factors affecting flu 
mortality in cities. We exploit plausibly exogenous variation in the presence of teams and the number of games that take place in a city. We also perform an event study of pre-trends in flu mortality, described below.

\subsubsection{Identification: Treatment Independence}

Variation in the presence of teams and number of games played in cities come from multiple sources, including entry of new teams, the timing of the first and last games played in each league in relation to flu season, and work stoppages leading to cancellation of a large number of games or an entire season. Figure A1 in the Appendix depicts the presence and absence of teams in all four professional sports leagues in the sample of cities in the CMRS data analyzed. A dark horizontal line indicates the presence of a sports team in that city in that year. Figure A1 shows substantial variation in the presence of teams in cities. Our primary DiD analysis takes advantage of the variation in the presence of sports teams in cities generated by the entry of new teams and the timing.

Variation in the presence of teams in cities generated by the entry of new teams can occur through several means. Rival sports leagues occasionally emerge to compete with existing leagues and existing leagues periodically expand to deter the formation of rival leagues (Che and Humphreys, 2015). Both of these events lead to the entry of new sports teams to cities, although rival leagues sometimes place teams in cities with a team in the incumbent league. The timing of rival sports league formation depends on the size and spatial distribution of existing leagues, demand for attendance at games, and the existence of sufficient wealthy individuals with an interest in owning a sports team. These events should be exogenous to unobservable time-varying city-specific factors that affect flu deaths. ${ }^{3}$

Another means through which cities acquire new teams is an existing team relocating

\footnotetext{
${ }^{3}$ Note that Appendix Figure A1 includes some teams from two rival leagues that formed during the sample period, the American Basketball Association (ABA), which formed in 1967 and partially merged with the NBA in 1976, and the World Hockey Association (WHA), which formed in 1972 and partially merged with the NHL in 1978. Four ABA teams joined the NBA: the Denver Nuggets, Indiana Pacers, New York Nets, and San Antonio Spurs. The only US-based WHA team to join the NHL was the Hartford Whalers. We treat these teams as members of the incumbent league throughout the sample period.
} 
from one city to another. This typically occurs when teams seeking a new stadium or arena to replace an older current home threaten to move to another city in order to extract a subsidy from the local government for new facility construction (Humphreys and Zhou, 2015). Teams move when the local government refuses to provide such a subsidy or when a different host promises a larger subsidy than the existing host city. The timing of teams moving to a new city depends on the expiry of a team's lease with their existing facility and other factors. The exit of a team under these conditions, especially the timing, should be exogenous to unobservable time-varying city-specific factors that affect flu mortality.

The main analysis in the present study takes advantage of plausibly exogenous variation in games played in a city generated by the entry of a team into the city. We focus on this form of variation because it closely resembles what cities will experience when professional sports leagues resume their COVID-19 interrupted seasons or start seasons that were delayed due to COVID-19 health concerns. If the timing of the first game of the first season a team played in a city is not related to unobservable factors affecting flu deaths, then the start of the first season for a new professional sports team in a city resembles an experiment that flips the switch on a "games occurred in this city" variable at a random time. If this condition is satisfied, then $\delta$ can be considered a causal estimate of the effect of "turning on" professional sports events on influenza mortality in that city.

We define treatment as outcomes where a professional sports team arrives in a city that was not previously home to a team in that league and stays in that city for the remainder of the sample period. This situation represents a one-time change in the no games/games switch in the host city. Correct estimation of standard errors in DiD models requires consistency in the treatment over time within treated cities. This requirement of consistency leads us to drop cities like Charlotte from the treated NBA cities, since Charlotte got a new NBA franchise in 1988, lost it to New Orleans in 2002, and gained another new NBA team in 2004. Similar non-constant treatments result in dropping other potential candidates like Cleveland, Houston, Saint Louis, Baltimore, and Hartford in other sports leagues. 
For cities home to an American Football League (AFL) or ABA team that merged into the NFL or NBA early in the sample, the start of play for the AFL or ABA team marks the entry of a team in a city. These league mergers should not affect flu transmission or mortality. Figure A1 in the appendix shows the universe of potential variation in teams playing games over the sample period.

Figure 1 shows the treatment period and treated cities in the sample for each sport. The graph in upper left hand corner of Figure 1 shows NHL teams in treated cities. Here we see that Buffalo welcomed an NHL team, the Sabres, in 1970 that remained in the city throughout the sample period. The graph in the upper right hand corner of Figure 1 depicts cities that became home to new teams in the NBA - the league with the most new entrants of the four professional leagues. The newest entrant to the NBA was the Memphis Grizzlies who began play there during the 2001-2002 NBA season. Moving down to the lower left hand corner of Figure 1, we see the 10 cities that became home to new NFL teams in our sample. This group includes Atlanta and Miami who became home to the Falcons and Dolphins respectively in 1966. Finally, cities welcoming new teams to MLB appear in the bottom right corner of Figure 1. In addition to the Falcons, Atlanta welcomed the Braves in 1966.

Figure 2 shows the average weekly flu mortality rate per 100,000 residents of a city in each week of the flu year. Following CDC convention, week 1 of the flu year contains the first full week of July and the final week of the flu year contains the end of June and, occasionally the first few days of July, periods of low seasonal flu mortality. The mortality rates shown in the figure are averaged across all cities and years in the sample for the treated cities that attracted an NBA, NFL, NHL, or MLB (black line) and the control cities that did not have a professional sports team over the sample period (grey line).

Note that weekly flu mortality in the control group exceeds that in treated cities throughout the flu year. Treated cities likely have better health care systems and smaller numbers of people vulnerable to the flu virus, for example younger, or higher income residents. The two vertical lines identify the first week of October and the last week of May. These lines 

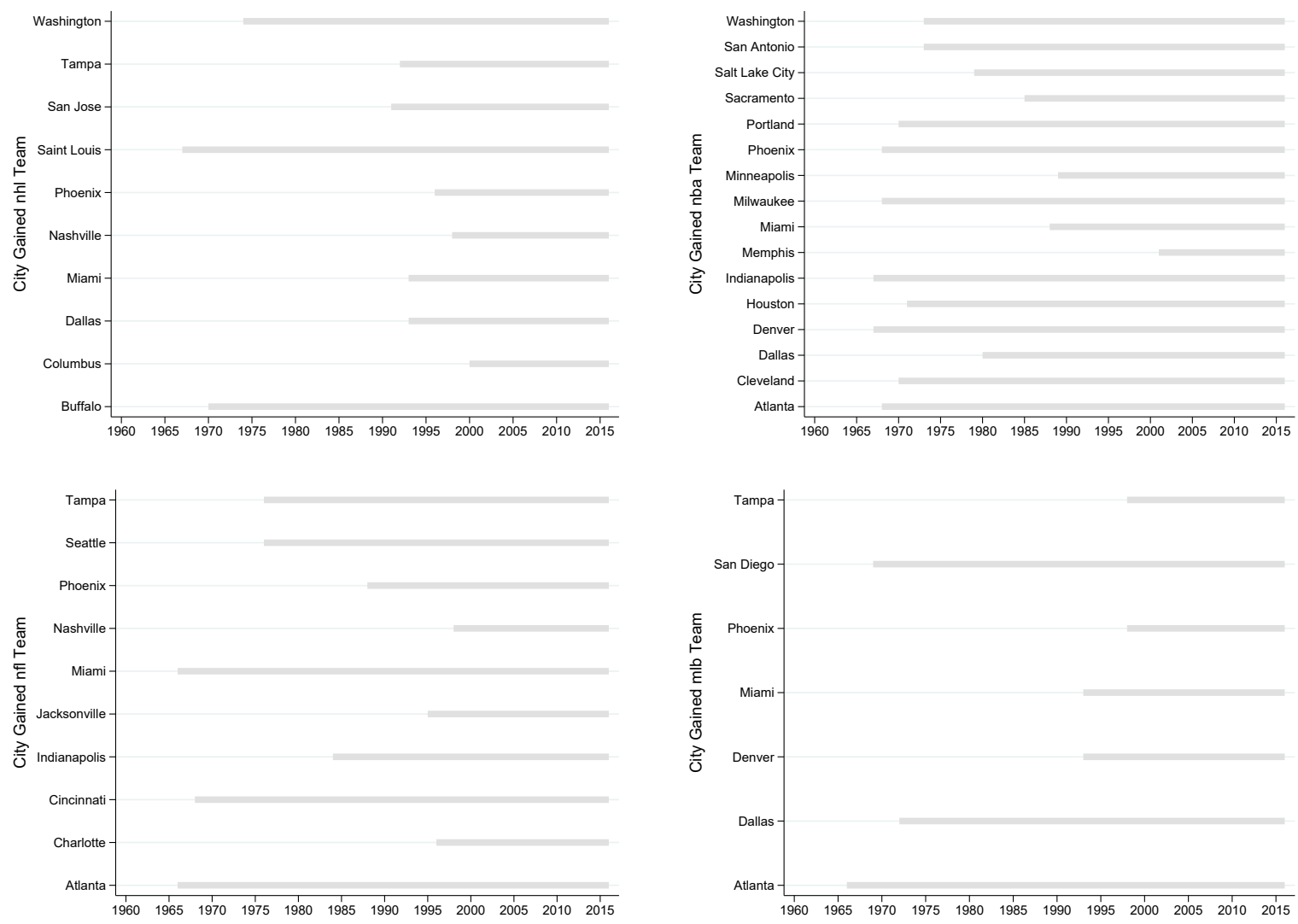

Figure 1: Treatment Period by Treated City and League

represent the start and end of the flu season, generally defined as early October and late May respectively. The CDC does not define a precise flu season. On average, flu mortality rates begin increasing in late September, spike and peak in January, and decline over the remainder of the flu year.

Another potential source of exogenous variation in exposure to games is the timing of the first game played in a city. Figure 2 also shows the duration of the average NBA, NHL, NFL and MLB seasons, including postseason play, as horizontal lines at the bottom of the graph. These lines provide a visualization of the differential timing of the season in each league in the context of the typical seasonal flu year. The NFL season starts prior to the flu season and the postseason occurs during peak flu season, a temporal feature exploited by Stoecker et al. (2016). The NHL and NBA seasons start in October or early November, 


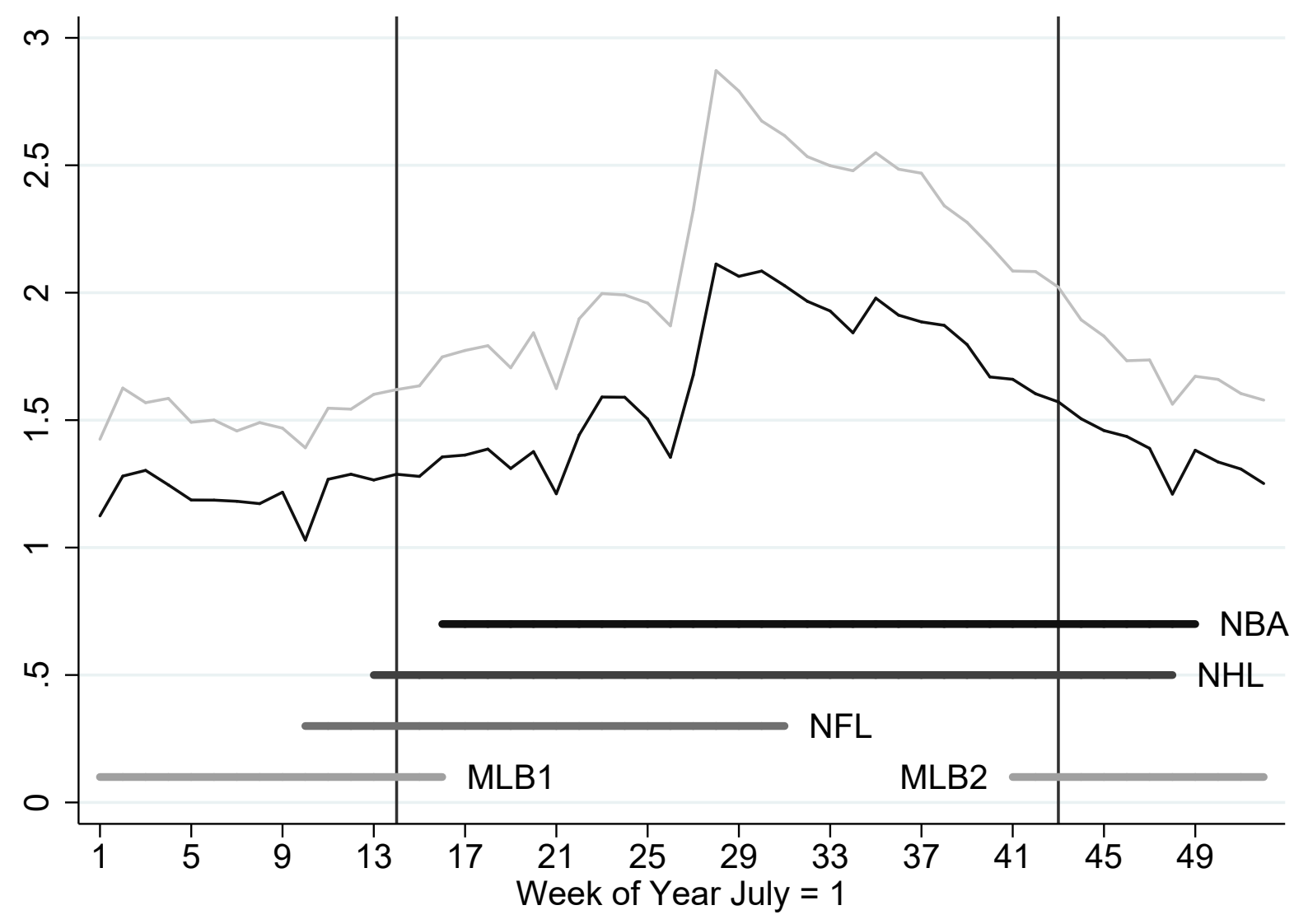

Figure 2: Average Flu Mortality Rate Per 100,000 Residents by Week of Flu Season

at or just after the onset of the flu season. Both the NBA and NHL season extend past the end of the flu season. The MLB season does not include much of the annual flu season but spans two different MLB seasons. The late regular season and postseason occurs in early flu season (MLB1 in Figure 2 ) and early regular season games the following season occur late in the same flu season (MLB2 in Figure 2).

These temporal differences in games likely leads to heterogeneity in the role played by games in each sport in influencing flu transmission, since this transmission works through infected to uninfected interactions. MLB games may not play as large a role in flu transmission as NBA games because fewer infected individuals exist in a city during the MLB season compared to during the NBA season. Since the flu season extends well beyond the end of 
MLB and NFL play in a city, their impact on flu deaths is more difficult to assess because of the time lags between transmissions at games and flu deaths. We estimate separate DiD models for each sport because of this heterogeneity. This variation in timing of the seasons over the flu year should generate different impacts on flu transmission and mortality that will be informative for an understanding of the role these games play in local health outcomes. This variation will also be useful information as local officials and leagues resume play following COVID-19 shutdowns in sports leagues around the world. ${ }^{4}$

In supplemental analyses, we explore work stoppages that result in the cancellation of games as exogenous shocks that alter social distancing patterns and the probability of flu transmission in the opposite direction. Strong unions exist among players in professional sports leagues in North America. These players' unions collectively bargain with leagues and team owners over the terms of employment that results in collective bargaining agreements (CBA). Unions and leagues often experience difficulty agreeing on CBAs leading to work stoppages that result in the cancellation of games, sometimes large numbers of games. In the most extreme case, the NHL cancelled the entire 2004-2005 season because of such a labor dispute. The factors leading to such disagreements should reflect national economic conditions, the conditions in past CBAs, and potentially past animosity between players' unions and team owners. These factors should be exogenous to unobservable time-varying city-specific factors that affect influenza mortality.

\subsubsection{Control Cities}

The DiD approach compares outcomes in treated areas to outcomes in control areas that do not receive the treatment. The control group embodies a counterfactual for the treated group and should closely resemble the treatment group except for the treatment. Cities that never had a professional sports team throughout the sample period represent a natural control

\footnotetext{
${ }^{4}$ In each sport-specific regression model, we exclude cities home to a team in that sport continuously throughout the 1962-2016 period from the sample since the continuous presence of a team in a city is observationally equivalent to a city-specific fixed effect and these cities also receive the treatment.
} 
group, given the focus here on cities where new sports teams entered as treated cities. The control group analyzed here includes all cities in the CMRS data that had no professional sports teams over the entire sample period. Youth, high school, and college sporting events occur in both treated and control cities, but many of these events do not attract the same number of fans as professional sporting events, and the length of the seasons differ from professional sports, providing temporal differences in their impact on flu transmission.

In terms of rival leagues, cities home to $\mathrm{ABA}$ teams that did not merge into the $\mathrm{ABA}$ are not included in the treatment or control group, since they did not have a professional basketball team throughout the sample. All AFL teams merged into the NFL.

Overlap exists in terms of population in the treated and control cities. The largest control cities include El Paso (650,000), Albuquerque (546,000), Tucson (520,000), Fresno (495,000), and Omaha (409,000). The smallest treated cities include Salt Lake City (186,000), Saint Louis (319,000), Atlanta (392,000), and Portland (581,000). As discussed in Section 3.3, cities in the CMRS data located in the metropolitan New York, Chicago, Los Angeles and San Francisco areas were dropped from the analysis sample because of possible identification problems in these cities.

\subsubsection{Identification: Pre-Trend Analysis}

The second key identifying assumption underlying the DiD approach to causal inference requires similar pre-treatment time paths of the outcome variable in the treatment and control groups and similar post-treatment time paths absent the impact of the treatment in the treated group, typically called the parallel trends assumption. This key assumption cannot be formally tested.

Figure A2 in the Appendix shows the time path of average annual flu mortality in the treated and control cities in the three years before and after the arrival of a new team in a treated city. Like other research using the DiD approach, we assess the plausibility of the parallel trends assumption by assessing whether the trends in flu deaths were similar across 
the treated and control cities prior to the arrival of a new team in each of four leagues. We do this assessment through an event study analysis. The event study model takes the form

$$
D_{c t}=\phi_{c}+\lambda_{t}+\sum_{\tau=-3}^{-1} \kappa_{\tau} D_{c \tau}+\sum_{\tau=0}^{3} \delta_{\tau} D_{c \tau}+\gamma C_{c t}+\varepsilon_{t c}
$$

where $D_{c t}$ is annual influenza mortality in city $c$ in flu year $t, \phi_{c}$ is a vector of city fixed effects, $\lambda_{t}$ is a vector of flu year fixed effects, $C_{c t}$ is a vector of time varying city-specific explanatory variables and $\varepsilon_{t c}$ is an unobservable, mean zero, heteroscedastic random variable capturing other factors affecting flu mortality. The indicator variable $D_{c \tau}$ is equal to one in the three years before and three years after a new team enters a treated city and equal to zero in all other years and in the control cities.

Figure 3 plots the results of estimating equation (2) in terms of point estimates and $95 \%$ confidence intervals for $\hat{\kappa_{\tau}}$ and $\hat{\delta_{\tau}}$ the relevant pre- and post-event parameters.

Figure 3 generally supports the parallel trends assumption. Zero lies in the 95\% confidence interval for all pre-treatment parameter estimates across all four leagues. There is no apparent difference in flu mortality prior to the arrival of a new professional sports team in a city. Flu mortality in treated cities was statistically similar to flu mortality in control cities in the three years before the arrival of a new team in the treated cities. We show post-treatment parameter estimates for completeness. The lack of any post-treatment differences in the three years following treatment does not reflect the DiD treatment used in the regression models. The DiD regression models assume a constant treatment after the arrival of a new team.

\subsection{Empirical Results}

We use our main differences-in-differences identification strategy, Equation (1), to analyze the impact of professional sports games occurring in a city on flu mortality in each flu year. We first evaluate the impact of a new professional NBA, NFL, NHL, or MLB team in a 

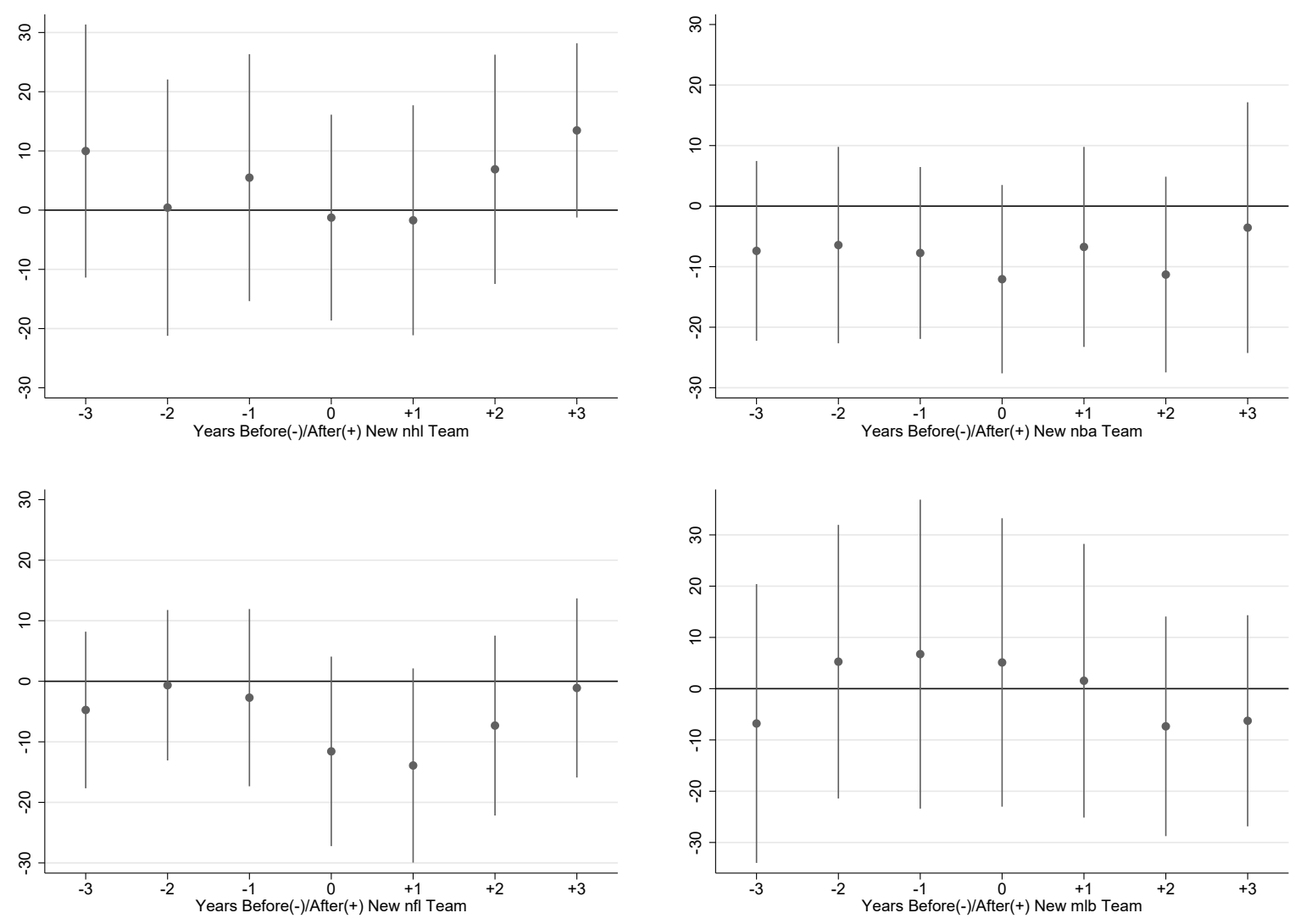

Figure 3: Pre and Post Treatment Event Study Parameter Estimates by League

city on flu mortality in that city. We focus on this form of variation because it most closely proxies what cities will experience when professional sports leagues resume play.

Our first set of results assess the impact of a professional sports team newly entering a city on weekly flu deaths in that city. In terms of the DiD indicator term in Equation (1), $\delta I\left(G_{w_{s}, w_{e}, i c}^{s}\right)$, we set $w_{s}$ equal to the week in which games were first played in each sport in each city and $w_{e}$ to the end of the sample period. The treated cities include only cities that gained one new team in each sport during the sample period and that remained in the city throughout the sample period. This model assesses the permanent effect of starting games in each sport in each city on influenza deaths and takes into account the weekly dynamics of flu transmission, and the time that elapses between transmission and death, throughout the flu season without specifying a lag structure for sporting events. This approach accounts for 
the impact of sporting events occurring in the treated cities in a general way.

Before presenting the DiD results from Equation 1, we first present the summary statistics for key variables in Equation (1), where the dependent variable is weekly flu deaths per 100,000 population, in Table 1. For each variable, we present the mean, followed by the standard deviation for the control and treated (newteam) cities in each of the four leagues.

Table 1: Means and Standard Deviations for New Team Dif-in-Dif Models, Weekly Data

\begin{tabular}{lcccccccc}
\hline & \multicolumn{2}{c}{ nhl } & \multicolumn{2}{c}{ nfl } & \multicolumn{2}{c}{ nba } & \multicolumn{2}{c}{ mlb } \\
\hline Flu Mortality Rate & & & & & & & & \\
Control & 1.989 & 0.005 & 2.003 & 0.005 & 1.986 & 0.005 & 2.022 & 0.005 \\
Newteam & 1.551 & 0.011 & 1.465 & 0.009 & 1.408 & 0.008 & 1.112 & 0.008 \\
\hline City Population & & & & & & & & \\
Control & 0.213 & 0.000 & 0.201 & 0.000 & 0.208 & 0.000 & 0.200 & 0.000 \\
Newteam & 0.648 & 0.003 & 0.585 & 0.002 & 0.723 & 0.002 & 0.801 & 0.003 \\
\hline Average Temperature & & & & & & & & \\
Control & 54.15 & 0.042 & 53.90 & 0.042 & 53.82 & 0.042 & 54.05 & 0.043 \\
Newteam & 59.61 & 0.140 & 62.09 & 0.119 & 57.93 & 0.095 & 64.51 & 0.129 \\
\hline Average Precipitation & & & & & & & & \\
Control & 3.291 & 0.005 & 3.329 & 0.005 & 3.291 & 0.005 & 3.275 & 0.005 \\
Newteam & 3.345 & 0.020 & 4.048 & 0.023 & 3.079 & 0.014 & 2.848 & 0.026 \\
\hline Observations & 189539 & & 189421 & & 206268 & & 181026 & \\
\hline
\end{tabular}

The weekly flu mortality rate is lower in cities that get new professional sports teams compared to cities in our sample that never had a team across the four major leagues. The mean number of weekly flu deaths per 100,000 residents in the control cities ranged from 1.986 in the NBA to 2.002 in MLB compared to 1.112 in MLB to 1.551 in the NFL in the treated cities. It is not surprising that the average population in cities that are home to new professional teams is higher than in cities without a professional sports teams since team owners will be attracted to more populous areas for attendance and television revenues reasons.

In terms of weather, cities with new teams are warmer on average than the control cities but not necessarily less rainy. The observed differences between weekly flu mortality 
and temperature across the treatment and control cities is supportive of our identifying assumption. If our results indicate flu mortality increases after a new team enters a city, then we can have confidence that the result is attributable to the team and not some systematic variation in flu deaths across the cities.

Table 2 summarizes the results from separate DiD models, given by Equation 1, for each professional sport. Recall, the parameter of interest, $\delta$, reflects the plausibly causal impact of the effect of turning on the switch of professional sports events on influenza mortality in that city if the assumptions underlying DiD models hold. These models contain city, flu year, month, and week fixed effects variables and city-specific linear time trends. The results for these parameters are not reported. Estimated t-statistics reported on Table 2 correct for heteroscedasticity using the standard White-Huber "sandwich" correction. Cameron and Miller (2015) point out that if treatment is as good as randomly assigned within clusters, no cluster correction is needed. We argue that the treatment here is as good as randomly assigned, as discussed above.

The estimates of $\delta$ on Table 2 are positive and significant across all four sports leagues and, as expected, vary in magnitude. The arrival of a new professional sports team in a city, and the commencement of play by that team, increases flu mortality in the city. The largest effect comes from a new NHL team. A new NHL team moving into a city and starting play causes an increase in weekly influenza mortality of 0.382 per 100,000 residents per flu season compared to cities with no professional sports teams. Based on the sample means on Table 1 , this result represents a $24.6 \%$ increase in weekly flu mortality per 100,000 residents or a total increase of about $20 \mathrm{flu}$ deaths over a year in each treated city. A new NFL team moving into a city causes an increase in annual influenza mortality rates of 0.249 per flu season, a $17 \%$ increase, equivalent to about 13 additional flu deaths over 52 weeks. A city that becomes home to a new NBA team experiences an increase in flu mortality rates of 0.066 which is a $4.7 \%$ increase. The effect of a new team on flu mortality is smallest in MLB where the entry of a new team results in an increase in flu mortality rates of 0.059 or a $5.3 \%$ 
Table 2: Effect of New Team on Local Weekly Influenza Mortality

\begin{tabular}{lcccc}
\hline & $\mathrm{b} / \mathrm{t}$ & $\mathrm{b} / \mathrm{t}$ & $\mathrm{b} / \mathrm{t}$ & $\mathrm{b} / \mathrm{t}$ \\
\hline New NHL Team & $0.382^{* * *}$ & - & - & - \\
& 20.47 & & & - \\
New NFL Team & - & $0.249^{* * *}$ & - & - \\
& & 16.22 & & $-0.066^{* * *}$ \\
New NBA Team & - & - & 4.82 & - \\
& & & - & $0.059^{* *}$ \\
New MLB Team & - & - & & 3.22 \\
& & & $-3.056^{* * *}$ \\
City Population & $-3.197^{* * *}$ & $-3.526^{* * *}$ & $-1.342^{* * *}$ & -4.00 \\
Average Temperature & $-0.013^{* * *}$ & $-0.014^{* * *}$ & $-0.013^{* * *}$ & $-0.013^{* * *}$ \\
& -18.76 & -20.64 & -20.89 & -18.78 \\
Average Precipitation & $0.011^{* * *}$ & $0.007^{* * *}$ & $0.013^{* * *}$ & $0.008^{* * *}$ \\
& 6.39 & 4.56 & 8.12 & 4.68 \\
\hline Observations & 189539 & 189421 & 206268 & 181026 \\
$R^{2}$ & 0.284 & 0.290 & 0.317 & 0.291 \\
\hline
\end{tabular}

Significance: ${ }^{*} .05,{ }^{* *} .01,{ }^{* * *}<.001$.

All models contain city, year, month, and week fixed effects, city-specific linear trends.

increase. These increases represent about 3 additional deaths over a 52 week flu year.

The DiD model, Equation (1), also contains variables reflecting city population, average temperature, and average precipitation. The parameter estimates for city population are negative and statistically different from zero at the $1 \%$ level in all four leagues. Larger cities experience lower flu mortality rates. This lower mortality rate for larger cities could reflect better health care in larger cities, or differences in social mixing of residents over time. It could also reflect more herd immunity in larger cities. Variables are also constructed to take into account the dominant flu strain in each season, as well as whether the season experienced a pandemic. Cities that get new professional sports teams are slightly warmer and experience slightly more rain than cities that do not have professional sports team.

Despite their similar seasons, the effect size in cities with new NHL teams exceeds the effect size in cities with new NBA teams. Several factors might explain this difference. The sample contains more treated NBA cities (16) than NHL cities (10) which could dilute the 
estimated impact in NBA cities. Many treated NBA cities gained teams early in the sample period, when the rival ABA formed in the late 1960s, while most treated cities gained NHL teams later in the sample, in the early 1990s. Only Memphis gained a new NBA team after 1990.

\section{Supplemental Analyses and Robustness Checks}

We conduct several supplemental analyses and robustness checks of our main results on the impact of new sports teams on weekly influenza mortality. These analyses have three objectives: (1) to document the robustness of the main results on Table 2 to commonly used alternative specifications in the existing DiD literature; (2) to explore other plausibly exogenous changes across flu seasons in the number of games played in a city that are uncorrelated with unobservable factors affecting flu deaths; and (3) to put our main results in context of existing results about the impact of economic events on influenza transmission and mortality in Stoecker et al. (2016) and Adda (2016).

\subsection{Standard Error Corrections}

A number of alternative standard error corrections appear in the DiD literature, including cluster correction and bootstrapping. Cameron and Miller (2015) extensively discuss this issue. The main issues involve a lack of within-cluster time variation and the effect of a relatively small number of treated units on standard error estimates that bias estimated standard errors down, and resulting inference based on these estimated standard errors. Downward bias in estimated standard errors can lead to incorrectly rejecting the null hypothesis of no difference between zero and the key DiD parameter estimate, $\hat{\delta}$ from Equation (1). We use two alternative approaches to estimating standard errors advocated by Cameron and Miller (2015): cluster correction by city and wild bootstrapping. Each approach entails strengths and weaknesses relative to typical robust estimated standard errors. 
Table 3: Robustness Check: Alternative Standard Error Estimates

\begin{tabular}{llrr} 
Sports League & Cluster Correction & Lower 95\% CI Value & Upper 95\% CI Value \\
\hline nhl & cluster correct by city & 0.187 & 0.576 \\
nhl & wild bootstrap & 0.346 & 0.416 \\
\hline nfl & cluster correct by city & -0.072 & 0.570 \\
nfl & wild bootstrap & 0.221 & 0.276 \\
\hline nba & cluster correct by city & -0.228 & 0.360 \\
nba & wild bootstrap & 0.039 & 0.093 \\
\hline mlb & cluster correct by city & -0.363 & 0.482 \\
mlb & wild bootstrap & 0.026 & 0.093 \\
\hline
\end{tabular}

Table 3 summarizes the results for alternative methods of estimating standard errors. The wild bootstrap correction for few clusters used follows the approach developed by MacKinnon and Webb (2018) that has the standard wild bootstrap as the limiting case. This approach works well when all clusters are either treated or untreated and have the same number of observations, as is the case here. It also requires the clusters to have the same variancecovariance matrix up to a scalar factor, which appears to also apply to this setting. ${ }^{5}$ Table 3 shows the estimated upper and lower $95 \%$ confidence interval values on the DiD parameters from Equation (1) shown on Table 2 for each sport.

Table 3 shows that the significance of the DiD parameter estimates for new NBA and MLB teams (presented on Table 2) demonstrate sensitivity to cluster correction by city. The statistical significance of the parameter estimate on the entry of a new NFL team shows some sensitivity to cluster correction, but zero is nearly not included in the $95 \%$ confidence interval for the NFL. The statistical significance of the parameter estimate for the entry of a new NHL team, the largest in percentage terms, is robust to both alternative standard error corrections. The statistical significance of the DiD parameter in all four sports remains robust to the wild bootstrap procedure for few clusters.

\footnotetext{
${ }^{5}$ We implement the wild bootstrap correction using the boottest Stata procedure described in Roodman et al. (2019) with 901 iterations.
} 


\subsubsection{Cities Treated Only Once}

From Figure 1, several cities appear in multiple treatment groups in the sample. Miami and Phoenix welcomed new teams in all four professional sports leagues over the sample period. Atlanta, Dallas, and Tampa/Saint Petersburg gained teams in three different leagues. Denver, Indianapolis, Nashville, and Washington gained teams in two different leagues. This appearance by the same cities in different treatment groups could impact identification, since the effect of later arriving teams could be captured by the DiD parameter of earlier arriving teams.

To address these cases, we re-estimate Equation (1) using an alternative treatment group consisting of cities that gained only one professional sports team over the sample period. For MLB, this amounts to a case study of San Diego, which gained the Padres in 1969. Jacksonville and Cincinnati represent treated NFL cities. Four treated NHL cities (Buffalo, Columbus, Saint Louis and San Jose) and nine treated NBA cities (Cleveland, Houston, Memphis, Milwaukee, Minneapolis, Portland, Sacramento, Salt Lake City, and San Antonio) remain in the treated groups for those two leagues.

Table 4: Effect of New Team on Local Weekly Influenza Mortality, Single Treatment Cities

\begin{tabular}{lcccc}
\hline & $\mathrm{b} / \mathrm{t}$ & $\mathrm{b} / \mathrm{t}$ & $\mathrm{b} / \mathrm{t}$ & $\mathrm{b} / \mathrm{t}$ \\
\hline New NHL Team & $0.723^{* * *}$ & - & - & - \\
& 24.79 & & & - \\
New NFL Team & - & $0.403^{* * *}$ & - & - \\
& & 13.09 & & \\
New NBA Team & - & - & $0.241^{* * *}$ & $0.439^{* * *}$ \\
& & & 11.64 & 10.18 \\
New MLB Team & - & - & - & 164284 \\
& & & & 0.278 \\
\hline Observations & 172690 & 169868 & 186748 & \\
$R^{2}$ & 0.272 & 0.281 & 0.300 & \\
\hline Significance: ${ }^{*} .05,{ }^{* *} .01, * * *<.001$. \\
All models contain city, year, month, and week fixed effects, city-specific linear trends.
\end{tabular}

Table 4 contains the results. Again, the DiD parameters of interest are positive and 
statistically significant. The results on Table 2 do not reflect the presence of new teams in different leagues entering treated cities. The parameter estimates on Table 4 are generally larger than those on Table 2, suggesting the inclusion of cities gaining new teams in different leagues biased the parameter estimates on Table 2 downward.

\subsection{Annual Influenza Mortality}

Stoecker et al. (2016) estimate their models explaining observed variation in local flu mortality using annual data for the over 65 population. Our data do not contain detailed information about influenza deaths by age; however, we do observe all cause mortality by age, which will be analyzed below. In order to compare our results to those reported in Stoecker et al. (2016), we estimate our main DiD model, Equation (1), using annual flu mortality for all ages as the dependent variable. This variable is created by aggregating the weekly flu mortality data reported in the CMRS to annual average flu mortality rates. This substantially reduces the sample size in the regression models.

Table 5 shows the summary statistics for key variables in Equation 1 for the annual average data. The annual average flu mortality rates are similar for treated cities in the four professional sports leagues. General patterns in average city population are identical to those using the weekly data, as are general patterns in the temperature and rainfall variables.

Table 6 summarizes the DiD results from estimating Equation 1 using annual average values, where the treatment group is cities that welcomed a new professional sports team in each league during the sample and kept that team throughout the sample period. This is the same treatment as used in Table 2 using weekly data. Table 6 reports only the parameter estimates for the key DiD parameter, $\hat{\delta}$ in Equation (1).

Table 6 provides additional support for the idea that playing games in professional sports leagues causes increases in local flu mortality in cities with teams, and indirect support for the idea that increased transmission represents the mechanism for the increase in mortality. An NHL team moving into a city and starting play causes an increase in annual influenza 
Table 5: Means and Standard Deviations for New Team Dif-in-Dif Models, Annual Data

\begin{tabular}{lcccccccc}
\hline & \multicolumn{2}{c}{ nhl } & \multicolumn{2}{c}{ nf } & \multicolumn{2}{c}{ nba } & \multicolumn{2}{c}{$\mathrm{mlb}$} \\
\hline Flu Mortality Rate & & & & & & & & \\
Control & 102.8 & 1.117 & 103.4 & 1.130 & 102.6 & 1.127 & 104.4 & 1.138 \\
Newteam & 79.61 & 2.695 & 75.18 & 2.360 & 72.37 & 2.516 & 57.46 & 2.255 \\
\hline City Population & & & & & & & & \\
Control & 0.212 & 0.003 & 0.200 & 0.002 & 0.206 & 0.003 & 0.198 & 0.002 \\
Newteam & 0.646 & 0.019 & 0.584 & 0.014 & 0.722 & 0.016 & 0.793 & 0.024 \\
\hline Average Temperature & & & & & & & & \\
Control & 45.27 & 0.153 & 44.99 & 0.149 & 44.88 & 0.150 & 45.18 & 0.157 \\
Newteam & 51.91 & 0.639 & 55.28 & 0.593 & 49.86 & 0.419 & 57.55 & 0.548 \\
\hline Average Precipitation & & & & & & & & \\
Control & 3.133 & 0.022 & 3.175 & 0.023 & 3.149 & 0.023 & 3.103 & 0.023 \\
Newteam & 3.069 & 0.061 & 3.746 & 0.106 & 3.070 & 0.068 & 2.667 & 0.100 \\
\hline Observations & 3672 & & 3672 & & 3996 & & 3510 & \\
\hline
\end{tabular}

Table 6: Effect of New Team on Local Annual Influenza Mortality

\begin{tabular}{lcccc}
\hline & $\mathrm{b} / \mathrm{t}$ & $\mathrm{b} / \mathrm{t}$ & $\mathrm{b} / \mathrm{t}$ & $\mathrm{b} / \mathrm{t}$ \\
\hline New NHL Team & $19.874^{* * *}$ & - & - & - \\
& 4.53 & & & - \\
New NFL Team & - & $13.272^{* * *}$ & - & - \\
& & 3.58 & & - \\
New NBA Team & - & - & 0.431 & - \\
& & & 0.12 & 3.039 \\
New MLB Team & - & - & - & 0.67 \\
& & & & 3510 \\
\hline Observations & 3672 & 3672 & 3996 & 0.586 \\
$R^{2}$ & 0.574 & 0.581 & 0.608 &
\end{tabular}

Significance: ${ }^{*} .05,{ }^{* *} .01,{ }^{* * *}<.001$.

All models contain city and year fixed effects and city-specific linear trends. 
mortality rates of 19.8 per 100,000 local population over the flu year. Based on the sample means on Table 5, this represents a $24.9 \%$ increase in flu mortality per 100,000 residents, very similar to the estimate from the weekly data. An NFL team moving into a city causes an increase in annual influenza mortality rates of 13.27 per flu year, a $17.6 \%$ increase. This magnitude is also very close to the impact found using weekly data.

The key DiD parameter estimates for new NBA and NHL teams are not statistically different from zero using annual data. The effects using weekly data were small, and the smaller sample size using annual data may not be large enough to precisely estimate this effect in these two professional sports.

\subsubsection{All Cause Mortality Age 65+}

Stoecker et al. (2016) find evidence that postseason success by local NFL teams increases annual influenza deaths for people aged 65 and older in counties home to NFL teams. We lack data on pneumonia and influenza deaths by age, but the CMRS data contains information on all cause mortality by age groups.

As a robustness check, we re-estimate the basic DiD model, Equation (1), using the annual all cause mortality rate per 100,000 residents age 65 and older in each treated city in the sample as the dependent variable. This variable reflects pneumonia and influenza deaths as well as all other causes of death. Influenza and pneumonia deaths represent an unknown fraction of all deaths. The annual average all cause mortality rate for residents over age 65 is about 5,000 per year in cities that got new professional sports teams and about 2,000 for cities that never had a professional sports team.

Table 7 shows the parameter estimates and t-statistics for only the key DiD parameter, $\hat{\delta}$, in Equation (1) for each sport. The regression models contain city annual population, average annual temperature, average annual rainfall, fixed effects terms, and city-specific linear time trends, but the parameter estimates for these variables are not reported for brevity.

Table 7 contains evidence generally supporting the idea that the additional flu deaths 
Table 7: Effect of New Team on Local 65+ Mortality

\begin{tabular}{lcccc}
\hline & $\mathrm{b} / \mathrm{t}$ & $\mathrm{b} / \mathrm{t}$ & $\mathrm{b} / \mathrm{t}$ & $\mathrm{b} / \mathrm{t}$ \\
\hline New NHL Team & $768.8^{* * *}$ & - & - & - \\
& 6.61 & & & - \\
New NFL Team & - & $887.6^{* * *}$ & - & - \\
& & 8.68 & & - \\
New NBA Team & - & - & 167.0 & $-737.2^{* * *}$ \\
& & & 1.72 & -7.01 \\
New MLB Team & - & - & - & 3510 \\
& & & & 0.921 \\
\hline Observations & 3672 & 3672 & 3996 & \\
$R^{2}$ & 0.912 & 0.915 & 0.916 & \\
\hline Significance: ${ }^{*} .05,{ }^{* *} .01,{ }^{* * *}<.001$. & & \\
All models contain city and year fixed effects and city-specific linear trends.
\end{tabular}

reported on Table 2 and Table 6 reflect increased flu and pneumonia deaths in the elderly population. All cause mortality in the population aged 65 and older was higher in cities that attracted new NHL and NFL teams relative to cities with no professional sports team, and relative to all cause mortality in these cities before the arrival of a new team. This finding could reflect increased flu mortality in this age group, consistent with the results in Stoecker et al. (2016) for cities home to NFL teams playing in the Super Bowl. It is also important to note that the parameter on the new NBA team is close to significant at conventional significance levels. Alternatively, these positive and statistically significant parameter estimates could reflect increases in deaths related to negative cardiovascular health outcomes stemming from sporting events in treated cities (Kloner et al., 2009, 2011; Leeka et al., 2010). In this case, the arrival of a new NFL or NHL team in a city generates a previously undetected negative local externality, higher death rates among elderly residents in the local area.

The results on Table 7 for new MLB teams suggests that new MLB teams moving into a city cause reductions in all cause mortality among local residents age 65 or older. The MLB treatment group contains only seven cities, all in the south or southwest. The treatment group for the other three leagues contain more treated cities. This could drive the result for 
new MLB teams on Table 7.

We estimated an additional model using annual flu mortality data to determine how our main findings relate to the results reported by Stoecker et al. (2016). We estimated a regression model that included an indicator variable for seasons when teams in treated cities made postseason appearances, and a model that included the number of home and away postseason games played in each treated city in each sport. Recall that Stoecker et al. (2016) used postseason NFL appearances in the Super Bowl as the treatment variable. We do not report the results because the parameter estimates on these postseason appearance variables were uniformly not statistically different from zero. This treatment definition differs from the approach in Stoecker et al. (2016) in that it is much broader. A team making a single postseason game appearance constitutes a treated city under this approach. This broader approach may not reflect the same treatment as used by Stoecker et al. (2016).

\subsection{Work Stoppages}

Our final supplemental analysis examines the effect of work stoppages in professional sports leagues on local influenza mortality rates. Work stoppages proxy the opposite effect of a new team entering a city in that they effectively turn off the game-based flu transmission switch. If no games occur in a city, proximity between infected and uninfected individuals does not decline because of attending games or gathering to watch games on television. This analysis puts our results in the context of Adda (2016), who explores the effect of another type of work stoppage (transportation strikes), on virus transmission, including seasonal flu.

We collected data on the timing and impact of work stoppages in professional sports from a number of secondary sources, including various media reports. We do not distinguish between strikes, initiated by players, and lockouts, initiated by team owners, because they

both result in the same outcome: games not being played or practice not occurring. Work stoppages in professional sports leagues always occur near the expiry of collective bargaining agreements (CBAs) between players' unions and leagues. We identify work stoppages by start 
and end dates. The start dates are the exact day, month and year when a work stoppage officially began and the end date is the exact day, month and year when play recommenced following new CBA ratification by both parties. Since the timing of these work stoppages depends on collective bargaining between players and team owners that reflect economic and financial conditions affecting the leagues, they should be plausibly exogenous to unobservable factors affecting the spread and mortality of seasonal influenza.

If games increase seasonal flu transmission, then not playing games should reduce transmission, and ultimately reduce flu mortality since fewer individuals in vulnerable populations would contract the virus. Given the focus on games as influenza transmission mechanisms, we analyze only the impact of strikes that resulted in the cancellation of games on influenza mortality rates. Other work stoppages occurred in the sample that did not result in the cancellation of any games. Nine work stoppages that resulted in the cancellation of games occurred in the sample period. Table 8 summarizes these work stoppages. Although two MLB work stoppages occurred during the sample period, we do not analyze the impact of those work stoppages because of the relatively small impact of MLB games on flu mortality from Table 2.

Table 8: Work Stoppage Characteristics

\begin{tabular}{llll}
\hline Sport & Start Date & End Date & Impact on Games \\
\hline NFL & $9 / 21 / 1982$ & $11 / 16 / 1982$ & 9 game regular season \\
& $9 / 22 / 1987$ & $10 / 15 / 1987$ & 15 game regular season \\
\hline NBA & $7 / 1 / 1998$ & $1 / 7 / 1999$ & 50 game regular season \\
& $7 / 1 / 2011$ & $12 / 8 / 2011$ & 66 game regular season \\
\hline NHL & $10 / 1 / 1994$ & $1 / 11 / 1995$ & 48 game regular season \\
& $9 / 16 / 2004$ & $7 / 22 / 2005$ & Entire $2004 / 5$ season lost \\
& $9 / 15 / 2012$ & $1 / 12 / 2013$ & 48 game regular season \\
\hline
\end{tabular}

Table 8 summarizes relevant information about the six work stoppages in the NFL, NBA, and NHL during the sample period. The 1987 NFL strike resulted in the cancellation of only 
one game in the usual 16 game NFL season, as the owners restarted the regular season using replacement players, forcing the NFL player's union to capitulate. The longest work stoppage resulted in the loss of the entire 2004-05 NHL season. All the work stoppages in the NBA and NHL extended into the annual flu season.

Table 9: Effect of Work Stoppages on Local Annual Influenza Mortality

\begin{tabular}{lccc}
\hline & $\mathrm{b} / \mathrm{t}$ & $\mathrm{b} / \mathrm{t}$ & $\mathrm{b} / \mathrm{t}$ \\
\hline NBA 1998 Work Stoppage & 13.342 & - & - \\
& 1.38 & & - \\
NBA 2011 Work Stoppage & $-14.285^{* *}$ & - & - \\
& -3.03 & & - \\
NHL 1994 Work Stoppage & - & -1.688 & - \\
& & -0.22 & - \\
NHL 2004 Work Stoppage & - & 4.560 & - \\
& & 0.93 & $-9.633^{*}$ \\
NHL 2012 Work Stoppage & - & -8.345 & -1.99 \\
& & -1.02 & 1.558 \\
NFL 1982 Work Stoppage & - & - & 0.28 \\
NFL 1987 Work Stoppage & - & - & 4482 \\
& & & 0.719 \\
\hline Observations & 4590 & 4158 & -716 \\
$R^{2}$ & 0.724 & 0.716 & \\
\hline
\end{tabular}

Significance: ${ }^{*} .05,{ }^{* *} .01,{ }^{* * *}<.001$.

All models contain city and year fixed effects and city-specific linear trends.

Table 9 shows the results when the start and end dates for the indicator variable in Equation (1) are set to the start and end of each work stoppage in each sport using annual data. This results in an indicator variable equal to one in cities with a team in each sport experiencing a work stoppage during the sample period. The control group again includes cities with no professional sports teams. Note that this is not a continuous treatment effect like the entry of a new team in a city. This treatment also turns on and off during the sample period at the same time in each city with a team in each sports league.

Table 9 contains some evidence that work stoppages affect local flu mortality in cities with professional sports teams. Flu mortality in the 2011/12 flu year was lower in cities with 
NBA teams than in cities with no professional sports team. Based on the average annual flu mortality rate in treated NBA cities on Table 5, this represents about a $25 \%$ decline in annual flu mortality in those cities. Flu mortality also declined in cities with NFL teams during the 1982 NFL work stoppage relative to the rate in cities without NFL teams. This parameter estimate represents about a $10 \%$ reduction in flu mortality in those treated cities.

The results on Table 9 show considerable heterogeneity. Other work stoppages had no effect on local flu mortality. This heterogeneity could reflect differences in the specific treated cities in terms of unobservable heterogeneity. The reduction in flu mortality from some work stoppages shows that the results in Adda (2016) extend to other settings, providing additional information about the impact of work stoppages on flu transmission.

\section{Conclusions}

This study examines the role played by a new MLB, NFL, NBA, and NHL teams in a city on local flu mortality. Introducing a new sport franchise into a city resembles what cities can expect to experience in the current coronavirus pandemic when shutting down professional sports events and then resuming play. New franchises in cities represent the "turning on" of professional sports after a period of interruption.

Using weekly CDC data from 1962 through 2016, our main DiD estimation reveals that welcoming new teams in all four leagues lead to an increase in flu mortality. For the current coronavirus pandemic, the results provide evidence that public health officials, city and state governments, as well as league and team executives need to exercise caution as they contemplate reopening professional sporting events to fans. Given the highly contagious nature of the coronavirus compared to the typical seasonal flu, bringing fans back into a sports stadium/arena could lead to a spike in cases in the home cities of these teams. In addition to professional sporting events, the results of the present study can extend to other large mass gatherings such as concerts, conferences, and conventions. 
Consistent with the results in Stoecker et al. (2016), we find a significant increase in all cause mortality rates for people over the age of 65 in cities with new teams in two of the four professional sports leagues. While the present study analyzes all cause mortality in the elderly population, and not flu related mortality, our similar results can provide caution to public health officials tasked with providing information to the general public in cities throughout the United States and the world about the reopening of sport and non-sport events during the current pandemic.

While the present research provides some timely information for decision makers, we also make a number of contributions to the academic literature. As mentioned earlier, our research relates closely to work by Stoecker et al. (2016), who analyzed the impact of NFL team postseason success on MSA-level flu mortality. Their findings regarding playoff teams did not take into account that teams also enjoyed considerable regular season success in games just prior to their treatment period. Our findings take these regular season games into account and provide additional evidence that regular season games also contribute to local seasonal influenza mortality. The impact of regular season games could explain part of the impact reported by Stoecker et al. (2016). We do not find an increase in annual flu mortality stemming from home and away playoff games.

Our results for the impact of work stoppages indicate heterogeneity in the effect of work stoppages in different leagues and time periods on local flu mortality, consistent with previous research by Adda (2016). We find that only the 1982 NFL work stoppage and the 2011 NBA work stoppage had a negative impact on flu mortality. The lack of any impact associated with the 2004 NHL work stoppage, which led to the cancellation of the entire season, on flu mortality represents a somewhat surprising finding. A possible explanation for this insignificant result could be that individuals who would have attend hockey games cancelled by the 2004 work stoppage decided to not stay home and instead participated in other local activities. This explanation is consistent with studies of the 2004 NHL work stoppage such as Winfree and Fort (2008), who reported substitution in attendance at sporting events. 
There are a number of areas to explore in future research. For example, future research could explore the outcome opposite to cities gaining new franchises, that is, evaluating the impact on flu mortality in cities that lose professional sport franchises. Another area for future research is to exploit the variation in the venues that house professional sports teams. These facilities vary in terms of size and the percent filled to capacity. For example, many NFL facilities are sold out and are generally much larger than venues in the other sports. Future research could explore these variations in facility size and attendance on communicable disease transmission. In addition, many modern facilities are considered "fully loaded", meaning they provide many amenities that enhance the experience for patrons. Facilities built in different building eras could potentially impact the transmission of flu and other airborne viruses such as COVID-19.

Another potential area for research is to look at non-sporting events like concerts. Previous research explored several factors related to these events such as congestion (Propheter, 2020). The facilities in the present study host more than just sporting events. Given the size of the venues, these non-sporting events can generate tens of thousands people. Thus, it is important for future research to look at these other events and their impact of flu transmission and mortality. A better understanding of this impact will inform the ongoing debates surrounding the desirability and appropriateness of tax-financed public subsidies for professional sport venues as most (if not all) of the venues in the present study receive some direct and/or indirect public financing. 


\section{References}

Adda, J. (2016). Economic activity and the spread of viral diseases: Evidence from high frequency data. The Quarterly Journal of Economics, 131(2):891-941.

Al-Tawfiq, J. A., Gautret, P., Benkouiten, S., and Memish, Z. A. (2016). Mass gatherings and the spread of respiratory infections: Lessons from the Hajj. Annals of the American Thoracic Society, 13(6):759-765.

American Academy of Pediatrics (2006). Preschoolers' respiratory illness predicts influenza mortality in all age groups. AAP Grand Rounds, 15(1):6-7.

Balkhy, H. H., Memish, Z. A., Bafaqeer, S., and Almuneef, M. A. (2004). Influenza a common viral infection among Hajj pilgrims: Time for routine surveillance and vaccination. Journal of Travel Medicine, 11(2):82-86.

Botelho-Nevers, E., Gautret, P., Benarous, L., Charrel, R., Felkai, P., and Parola, P. (2010). Travel-related influenza A/H1N1 infection at a rock festival in Hungary: One virus may hide another one. Journal of Travel Medicine, 17(3):197-198.

Brownstein, J. S., Kleinman, K. P., and Mandl, K. D. (2005). Identifying pediatric age groups for influenza vaccination using a real-time regional surveillance system. American Journal of Epidemiology, 162(7):686-693.

Cameron, A. C. and Miller, D. L. (2015). A practitioner's guide to cluster-robust inference. Journal of Human Resources, 50(2):317-372.

Cauchemez, S., Valleron, A.-J., Boelle, P.-Y., Flahault, A., and Ferguson, N. M. (2008). Estimating the impact of school closure on influenza transmission from Sentinel data. Nature, 452(7188):750-754.

Centers for Disease Control and Prevention (2020). U.S. Outpatient Influenza-like Illness Surveillance Network (ILINet). Data retrieved from Center for Disease Control 
and Prevention's website - U.S. Outpatient Influenza-like Illness Surveillance Network, https://gis.cdc.gov/grasp/fluview/fluportaldashboard.html.

Che, X. and Humphreys, B. R. (2015). Competition between sports leagues: Theory and evidence on rival league formation in North America. Review of Industrial Organization, $46(2): 127-143$.

Duncan, B., Mansour, H., and Rees, D. I. (2017). It's just a game: The Super Bowl and low birth weight. Journal of Human Resources, 52(4):946-978.

ESPN News Services (2020). NBA suspends season until further notice after player tests positive for the coronavirus. ESPN.com. Retrieved May 30, 2020, from https://www.espn.com/nba/story/_/id/28887560/ nba-suspends-season-further-notice-player-tests-positive-coronavirus.

Gautret, P. and Steffen, R. (2016). Communicable diseases as health risks at mass gatherings other than Hajj: What is the evidence? International Journal of Infectious Diseases, $47: 46-52$.

Giuffrida, A. (2020). Bergamo mayor says football match escalated infections in Italian province. The Guardian. Retrieved June 6, 2020, from https://www.theguardian.com/world/2020/mar/24/ bergamo-mayor-says-football-match-escalated-coronavirus-infections-italian-province.

Greene, S. K., Ionides, E. L., and Wilson, M. L. (2006). Patterns of influenza-associated mortality among US elderly by geographic region and virus subtype, 1968-1998. American Journal of Epidemiology, 163(4):316-326.

Gundlapalli, A. V., Rubin, M. A., Samore, M. H., Lopansri, B., Lahey, T., McGuire, H. L., Winthrop, K. L., Dunn, J. J., Willick, S. E., and Vosters, R. L. (2006). Influenza, winter Olympiad, 2002. Emerging Infectious Diseases, 12(1):144-146. 
Gutiérrez, I., Litzroth, A., Hammadi, S., Van Oyen, H., Gerard, C., Robesyn, E., Bots, J., Faidherbe, M., and Wuillaume, F. (2009). Community transmission of Influenza A (H1N1) virus at a rock festival in Belgium, 2-5 July 2009. Eurosurveillance, 14(31):19294.

Humphreys, B. R. and Zhou, L. (2015). Reference-dependent preferences, team relocations, and major league expansion. Journal of Economic Behavior \& Organization, 109:10-25.

Kloner, R. A., McDonald, S., Leeka, J., and Poole, W. K. (2009). Comparison of total and cardiovascular death rates in the same city during a losing versus winning Super Bowl championship. The American Journal of Cardiology, 103(12):1647-1650.

Kloner, R. A., McDonald, S. A., Leeka, J., and Poole, W. K. (2011). Role of age, sex, and race on cardiac and total mortality associated with Super Bowl wins and losses. Clinical Cardiology, 34(2):102-107.

Krieger, N., Chen, J. T., Waterman, P. D., Kiang, M. V., and Feldman, J. (2015). Police killings and police deaths are public health data and can be counted. PLoS medicine, $12(12)$

Leeka, J., Schwartz, B. G., and Kloner, R. A. (2010). Sporting events affect spectators' cardiovascular mortality: It is not just a game. The American Journal of Medicine, 123(11):972-977.

MacKinnon, J. G. and Webb, M. D. (2018). The wild bootstrap for few (treated) clusters. The Econometrics Journal, 21(2):114-135.

Mangrum, D. and Niekamp, P. (2020). College student contribution to local COVID-19 Spread: Evidence from University Spring Break Timing. Working Paper 3606811, SSRN.

Propheter, G. (2020). Do urban sports facilities have unique social costs? An analysis of event-related congestion on police response time. International Journal of Urban Sciences, $24(2): 271-281$. 
Roodman, D., Nielsen, M. Ø., MacKinnon, J. G., and Webb, M. D. (2019). Fast and wild: Bootstrap inference in Stata using boottest. The Stata Journal, 19(1):4-60.

Simonsen, L., Clarke, M. J., Schonberger, L. B., Arden, N. H., Cox, N. J., and Fukuda, K. (1998). Pandemic versus epidemic influenza mortality: A pattern of changing age distribution. The Journal of Infectious Diseases, 178(1):53-60.

Soebiyanto, R. P., Adimi, F., and Kiang, R. K. (2010). Modeling and predicting seasonal influenza transmission in warm regions using climatological parameters. PloS one, 5(3).

Stoecker, C., Sanders, N. J., and Barreca, A. (2016). Success is something to sneeze at: Influenza mortality in cities that participate in the Super Bowl. American Journal of Health Economics, 2(1):125-143.

Viboud, C., Miller, M., Olson, D. R., Osterholm, M., and Simonsen, L. (2010). Preliminary estimates of mortality and years of life lost associated with the 2009 A/H1N1 pandemic in the US and comparison with past influenza seasons. PLoS Currents, 2.

Williams, C. J., Schenkel, K., Eckmanns, T., Altmann, D., and Krause, G. (2009). FIFA World Cup 2006 in Germany: Enhanced surveillance improved timeliness and detection. Epidemiology $\&$ Infection, 137(4):597-605.

Winfree, J. A. and Fort, R. (2008). Fan substitution and the 2004-05 NHL lockout. Journal of Sports Economics, 9(4):425-434. 


\section{Appendix}

\section{City-level Data Manipulation}

The paper exploits variation in the presence of professional sports teams across cities over time. Figure A1 shows the presence of NHL, NFL, NBA and MLB teams in US cities over the period 1962-2016.
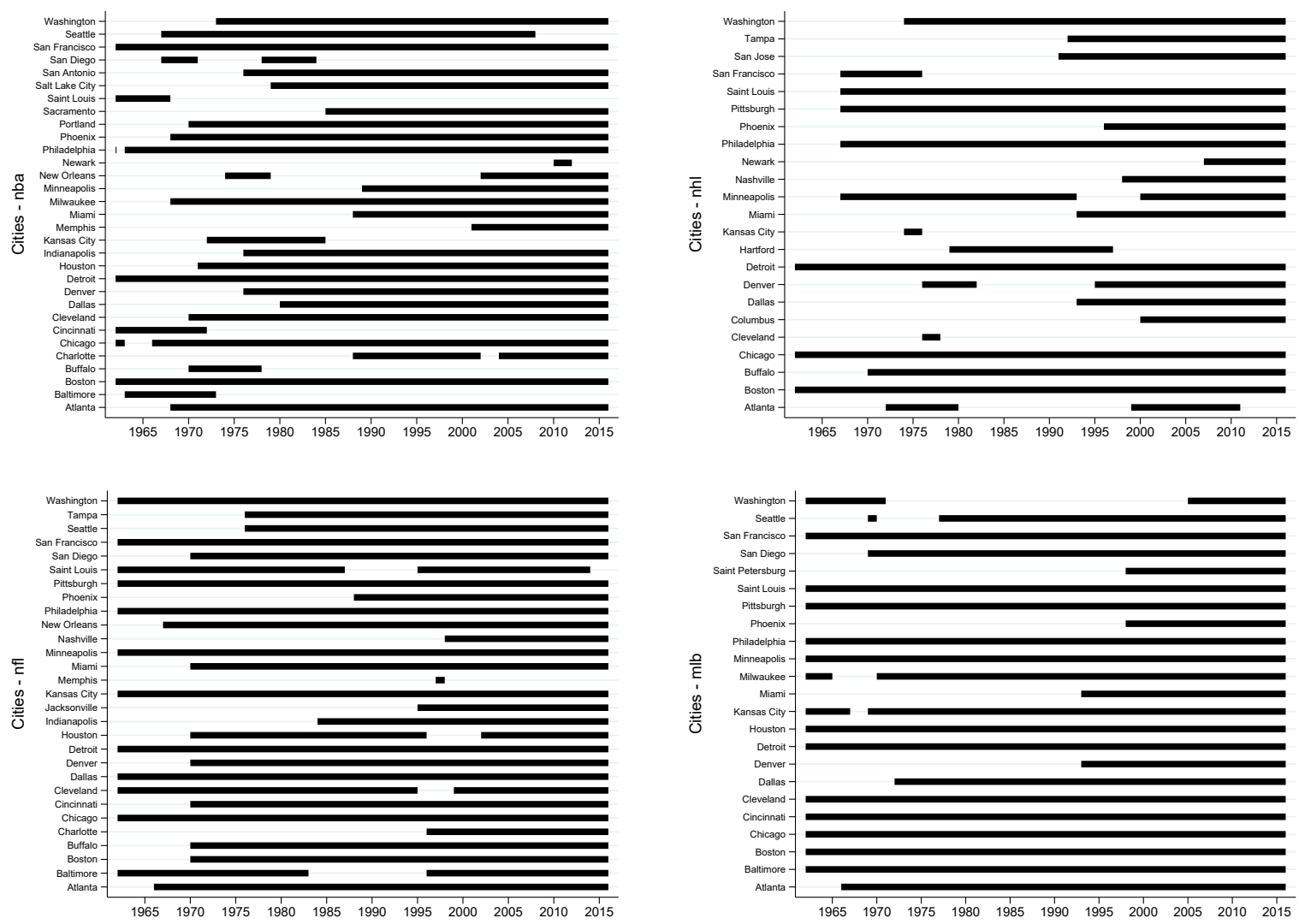

Figure A1: Team Presence by Professional Sports League and City 
Table A1: Cities in CDC CMRS Influenza Death Data

\begin{tabular}{|c|c|c|c|c|c|c|c|c|c|}
\hline City & State & Start & End & Status & City & State & Start & End & Status \\
\hline Akron & $\mathrm{OH}$ & 1962 & 2016 & & Miami & FL & 1962 & 2016 & TTTT \\
\hline Albany & NY & 1962 & 2016 & & Milwaukee & WI & 1962 & 2016 & $\mathrm{~T}$ \\
\hline Albuquerque & NM & 1962 & 2016 & & Minneapolis & $\mathrm{MN}$ & 1962 & 2016 & $\mathrm{~T}$ \\
\hline Allentown & $\mathrm{PA}$ & 1962 & 2016 & & Mobile & $\mathrm{AL}$ & 1962 & 2016 & \\
\hline Atlanta & GA & 1962 & 2016 & $\mathrm{TTT}$ & Montgomery & $\mathrm{AL}$ & 1962 & 2016 & \\
\hline Austin & $\mathrm{TX}$ & 1962 & 2016 & & Nashville & $\mathrm{TN}$ & 1962 & 2016 & $\mathrm{TT}$ \\
\hline Baltimore & $\mathrm{MD}$ & 1962 & 2016 & & New Bedford & MA & 1962 & 2016 & \\
\hline Baton Rouge & LA & 1962 & 2016 & $\mathrm{X}$ & New Haven & $\mathrm{CT}$ & 1962 & 2016 & \\
\hline Berkeley & $\mathrm{CA}$ & 1962 & 2016 & & New Orleans & LA & 1962 & 2016 & $\mathrm{X}$ \\
\hline Birmingham & $\mathrm{AL}$ & 1962 & 2016 & & New York & NY & 1962 & 2016 & $\mathrm{X}$ \\
\hline Boise & ID & 1997 & 2016 & $\mathrm{X}$ & Newark & NJ & 1962 & 2016 & $\mathrm{X}$ \\
\hline Boston & MA & 1962 & 2016 & & Norfolk & $\mathrm{VA}$ & 1962 & 2016 & \\
\hline Bridgeport & $\mathrm{CT}$ & 1962 & 2016 & & Ogden & $\mathrm{UT}$ & 1962 & 2016 & \\
\hline Buffalo & NY & 1962 & 2016 & $\mathrm{~T}$ & Omaha & $\mathrm{NE}$ & 1962 & 2016 & \\
\hline Cambridge & MA & 1962 & 2016 & & Pasadena & $\mathrm{CA}$ & 1962 & 2016 & $\mathrm{X}$ \\
\hline Camden & NJ & 1962 & 2016 & $\mathrm{X}$ & Paterson & NJ & 1962 & 2016 & $\mathrm{X}$ \\
\hline Canton & $\mathrm{OH}$ & 1962 & 2016 & & Peoria & IL & 1962 & 2016 & \\
\hline Charlotte & $\mathrm{NC}$ & 1962 & 2016 & $\mathrm{~T}$ & Philadelphia & $\mathrm{PA}$ & 1962 & 2013 & $\mathrm{X}$ \\
\hline Chattanooga & $\mathrm{TN}$ & 1962 & 2016 & & Phoenix & $\mathrm{AZ}$ & 1962 & 2016 & TTTT \\
\hline Chicago & IL & 1962 & 2016 & $\mathrm{X}$ & Pittsburgh & $\mathrm{PA}$ & 1962 & 2015 & $\mathrm{X}$ \\
\hline Cincinnati & $\mathrm{OH}$ & 1962 & 2016 & $\mathrm{~T}$ & Portland & OR & 1962 & 2016 & $\mathrm{~T}$ \\
\hline Cleveland & $\mathrm{OH}$ & 1962 & 2016 & $\mathrm{~T}$ & Providence & RI & 1962 & 2016 & \\
\hline Colorado Springs & $\mathrm{CO}$ & 1962 & 2016 & & Pueblo & $\mathrm{CO}$ & 1962 & 2016 & \\
\hline Columbus & $\mathrm{OH}$ & 1962 & 2016 & $\mathrm{~T}$ & Reading & $\mathrm{PA}$ & 1962 & 2016 & \\
\hline Corpus Christi & $\mathrm{TX}$ & 1962 & 2016 & & Richmond & $\mathrm{VA}$ & 1962 & 2016 & \\
\hline Dallas & $\mathrm{TX}$ & 1962 & 2016 & TTT & Rochester & NY & 1962 & 2016 & \\
\hline Dayton & $\mathrm{OH}$ & 1962 & 2016 & & Rockford & IL & 1962 & 2016 & \\
\hline Denver & $\mathrm{CO}$ & 1962 & 2016 & $\mathrm{TT}$ & Sacramento & $\mathrm{CA}$ & 1962 & 2016 & $\mathrm{~T}$ \\
\hline Des Moines & IA & 1962 & 2016 & & Saint Louis & MO & 1962 & 2016 & $\mathrm{~T}$ \\
\hline Detroit & MI & 1962 & 2016 & & Saint Paul & $\mathrm{MN}$ & 1962 & 2016 & $\mathrm{~T}$ \\
\hline Duluth & $\mathrm{MN}$ & 1962 & 2016 & & Saint Petersburg & $\mathrm{FL}$ & 1962 & 2016 & TTT \\
\hline El Paso & $\mathrm{TX}$ & 1962 & 2016 & & Salt Lake City & $\mathrm{UT}$ & 1962 & 2016 & $\mathrm{~T}$ \\
\hline Elizabeth & NJ & 1962 & 2016 & $\mathrm{X}$ & San Antonio & $\mathrm{TX}$ & 1962 & 2016 & $\mathrm{~T}$ \\
\hline Erie & $\mathrm{PA}$ & 1962 & 2016 & & San Diego & $\mathrm{CA}$ & 1962 & 2016 & $\mathrm{~T}$ \\
\hline Evansville & IN & 1962 & 2016 & & San Francisco & $\mathrm{CA}$ & 1962 & 2016 & $\mathrm{X}$ \\
\hline Fall River & MA & 1962 & 2016 & & San Jose & $\mathrm{CA}$ & 1962 & 2016 & $\mathrm{~T}$ \\
\hline Fort Wayne & IN & 1962 & 2016 & & Santa Cruz & $\mathrm{CA}$ & 1991 & 2016 & \\
\hline Fort Worth & $\mathrm{TX}$ & 1962 & 2009 & $\mathrm{X}$ & Savannah & GA & 1962 & 2016 & \\
\hline Fresno & $\mathrm{CA}$ & 1962 & 2016 & & Schenectady & NY & 1962 & 2016 & \\
\hline Gary & IN & 1962 & 2016 & & Scranton & $\mathrm{PA}$ & 1962 & 2016 & \\
\hline Glendale & $\mathrm{CA}$ & 1962 & 2016 & $\mathrm{X}$ & Seattle & WA & 1962 & 2016 & $\mathrm{~T}$ \\
\hline Grand Rapids & MI & 1962 & 2016 & & Shreveport & LA & 1962 & 2016 & \\
\hline Hartford & $\mathrm{CT}$ & 1962 & 2016 & & Somerville & MA & 1962 & 2016 & \\
\hline Honolulu & HI & 1962 & 2016 & & South Bend & IN & 1962 & 2016 & \\
\hline Houston & $\mathrm{TX}$ & 1962 & 2016 & $\mathrm{~T}$ & Spokane & WA & 1962 & 2016 & \\
\hline Indianapolis & IN & 1962 & 2016 & $\mathrm{TT}$ & Springfield & MA & 1962 & 2016 & \\
\hline Jacksonville & $\mathrm{FL}$ & 1962 & 2016 & $\mathrm{~T}$ & Syracuse & NY & 1962 & 2016 & \\
\hline Jersey City & NJ & 1962 & 2016 & $\mathrm{X}$ & Tacoma & WA & 1962 & 2016 & \\
\hline Kansas City & $\mathrm{KS}$ & 1962 & 2016 & & Tampa & $\mathrm{FL}$ & 1962 & 2016 & TTT \\
\hline Kansas City & MO & 1962 & 2016 & & Toledo & $\mathrm{OH}$ & 1962 & 2016 & \\
\hline Knoxville & $\mathrm{TN}$ & 1962 & 2016 & & Trenton & NJ & 1962 & 2016 & \\
\hline Lansing & MI & 1997 & 2016 & $\mathrm{X}$ & Tucson & $\mathrm{AZ}$ & 1962 & 2016 & \\
\hline Las Vegas & NV & 1968 & 2016 & $\mathrm{X}$ & Tulsa & $\mathrm{OK}$ & 1962 & 2016 & \\
\hline Lexington & KY & 1997 & 2016 & $\mathrm{X}$ & Utica & NY & 1962 & 2016 & \\
\hline Lincoln & $\mathrm{NE}$ & 1962 & 2016 & & Washington & $\mathrm{DC}$ & 1962 & 2016 & $\mathrm{TT}$ \\
\hline Little Rock & $\mathrm{AR}$ & 1962 & 2016 & & Waterbury & $\mathrm{CT}$ & 1962 & 2016 & \\
\hline Long Beach & $\mathrm{CA}$ & 1962 & 2016 & $\mathrm{X}$ & Wichita & KS & 1962 & 2016 & \\
\hline Los Angeles & $\mathrm{CA}$ & 1962 & 2016 & $\mathrm{X}$ & Wilmington & $\mathrm{DE}$ & 1962 & 2016 & \\
\hline Lowell & MA & 1962 & 2016 & & Worcester & MA & 1962 & 2016 & \\
\hline Lynn & MA & 1962 & 2016 & & Yonkers & NY & 1962 & 2016 & $\mathrm{X}$ \\
\hline Memphis & $\mathrm{TN}$ & 1962 & 2016 & $\mathrm{~T}$ & Youngstown & $\mathrm{OH}$ & 1962 & 2016 & \\
\hline
\end{tabular}

T: Treated; X: Dropped from sample. 
Table A2 contains detailed descriptions of city-level data from the CMRS combined and cities dropped from the sample.

Table A2: City-level Data Manipulation and Exclusions

\begin{tabular}{|c|c|c|}
\hline Cities (State) & Sports Situation & Unique Factors \\
\hline \multicolumn{3}{|c|}{ Data Combined for Cities } \\
\hline Kansas City, MO \& Kansas City, KS & Chiefs (NFL), Royals (MLB) & Stadiums in far east of $\mathrm{KC}, \mathrm{MO}$ \\
\hline Minneapolis \& St. Paul, (MN) & $\begin{array}{l}\text { Timberwolves (NBA), Vikings (NFL), } \\
\text { Wild (NHL), and Twins (MLB) }\end{array}$ & $\begin{array}{l}\text { Contiguous. Teams play in, draw fans } \\
\text { from both cities }\end{array}$ \\
\hline Tampa \& St. Petersburg (FL) & $\begin{array}{l}\text { Buccaneers (NFL), Devil Rays (MLB), } \\
\text { Lightning (NHL) }\end{array}$ & $\begin{array}{l}\text { Contiguous. Teams play in, draw fans } \\
\text { from both cities. }\end{array}$ \\
\hline Boston \& Cambridge (MA) & $\begin{array}{l}\text { Celtics (NBA), Patriots (NFL), Bruins } \\
(\mathrm{NHL}), \text { Red Sox (MLB) }\end{array}$ & $\begin{array}{l}\text { Patriots moved to Foxboro in } 1971 . \\
\text { The Celtics and Bruins play close to } \\
\text { both cities. }\end{array}$ \\
\hline Seattle \& Tacoma (WA) & $\begin{array}{l}\text { Supersonics (NBA) (1967-2008), Sea- } \\
\text { hawks (NFL), Mariners (MLB) }\end{array}$ & $\begin{array}{l}\text { Supersonics played in Tacoma for the } \\
\text { entire 1994/95 season. }\end{array}$ \\
\hline \multicolumn{3}{|c|}{ Excluded Cities } \\
\hline Chicago (IL) & $\begin{array}{l}\text { Bears (NFL), Blackhawks (NHL), Bulls } \\
\text { (NBA), Cubs \& White Sox (MLB) }\end{array}$ & $\begin{array}{l}\text { Almost no in-sample variation in team } \\
\text { presence (no NBA team in } 1964,1965 \text { ) }\end{array}$ \\
\hline Fort Worth (TX) & Cowboys (NFL), Rangers (MLB) & Missing flu mortality data after 2007 \\
\hline San Francisco \& Berkeley (CA) & $\begin{array}{l}\text { Warriors (NBA), 49ers (NFL), Sharks } \\
\text { (NHL), Giants (MLB) }\end{array}$ & $\begin{array}{l}\text { Giants (MLB) and 49ers (NFL) played } \\
\text { outside cities. Warriors (NBA) played } \\
\text { in Oakland. }\end{array}$ \\
\hline $\begin{array}{l}\text { Los Angeles, Long Beach, Glendale, \& } \\
\text { Pasadena (CA - Los Angeles area) }\end{array}$ & $\begin{array}{l}\text { Dodgers \& Angels (MLB), Lakers \& } \\
\text { Clippers (since 1984; NBA), Rams } \\
\text { (1962-1994, 2016) \& Raiders (1982- } \\
\text { 1994; NFL), Kings \& Ducks (1993- } \\
\text { 2016; NHL) }\end{array}$ & $\begin{array}{l}\text { City of Los Angeles has odd shape. An- } \\
\text { gels and Ducks play in Anaheim. No } \\
\text { NFL team in area for decades. Three } \\
\text { teams share one facility. }\end{array}$ \\
\hline Camden NJ \& Philadelphia PA & $\begin{array}{l}\text { Phillies (MLB), 76ers (NBA), Flyers } \\
(\mathrm{NHL}) \text {, Eagles (NFL) }\end{array}$ & $\begin{array}{l}\text { Philadelphia missing three years of } \\
\text { data at end of the sample. }\end{array}$ \\
\hline Pittsburgh, PA & $\begin{array}{l}\text { Pirates (MLB), Penguins (NHL), Steel- } \\
\text { ers (NFL) }\end{array}$ & $\begin{array}{l}\text { CDC flagged Pittsburgh reports as in- } \\
\text { complete, missing data for } 2015-16\end{array}$ \\
\hline
\end{tabular}




\begin{tabular}{l|l|l}
$\begin{array}{l}\text { Elizabeth, Jersey City, Newark \& Pa- } \\
\text { terson (NJ - northern area) }\end{array}$ & $\begin{array}{l}\text { Giants (1976-2016) \& Jets (1984-2016; } \\
\text { NFL), Nets (1977-2011; NBA), Devils } \\
\text { (NHL) }\end{array}$ & $\begin{array}{l}\text { All in close proximity. Nets played in } \\
\text { Newark 2010-2012. All near the Mead- } \\
\text { owlands where Giants, Jest, and Nets } \\
\text { played. }\end{array}$ \\
\hline New York City \& Yonkers (NY) & $\begin{array}{l}\text { Knicks \& Nets (1976, 2012-2016; } \\
\text { NBA), Rangers \& Islanders (NHL), } \\
\text { Mets \& Yankees (MLB), Jets (1969- } \\
\text { 1983) \& Giants (1962-1972, 1975; NFL) }\end{array}$ & $\begin{array}{l}\text { MY Jeam moves within New York } \\
\text { Nlayed in Nassau County, Long Island. }\end{array}$ \\
\hline
\end{tabular}




\section{Average Annual Flu Mortality Pre- and Post-treatment}

Figure A2 shows pre- and post-trends in annual influenza mortality rates in treated cities that gained new teams in each sport (dark line) and control cities with no teams during our sample period (grey line) for each sport. The vertical line at zero indicates the year when a new professional sports team began playing in the city. Trends in annual influenza rates in the treated and control cities are shown for the three prior to and after arrival of the new team. The parallel trends assumption is mostly supported by these graphs, particularly for the NBA, NFL, and MLB. The annual flu mortality rates in the treated and control cities follow common trends in the years prior to a new professional sports team arriving in a city but then diverge in the years following the entry of the team.
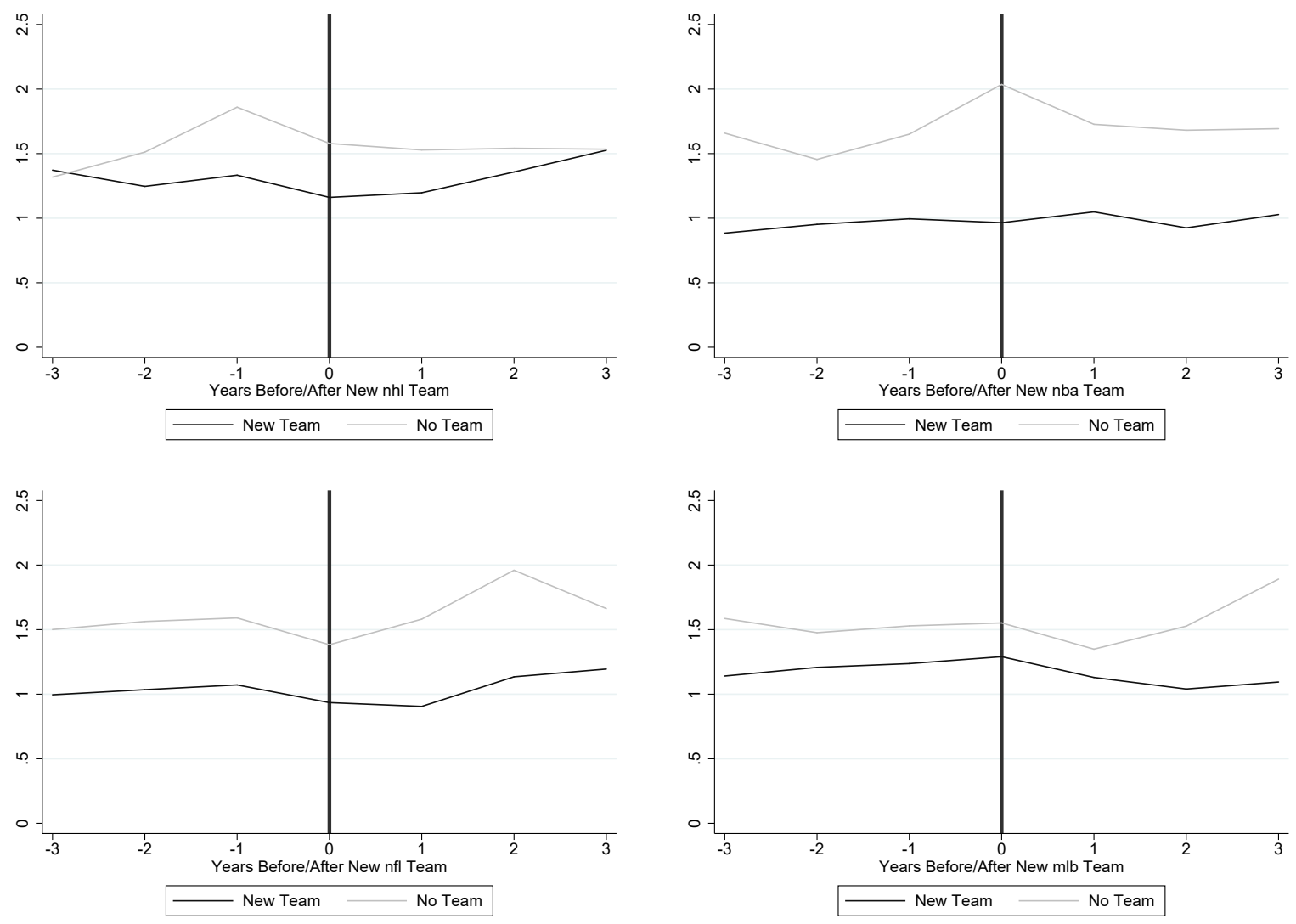

Figure A2: Pre and Post Treatment Trends by League 


\section{Circulating Flu Strains by Flu Season}

Figure A3 summarizes the different strains of influenza circulating in each flu season in the sample.

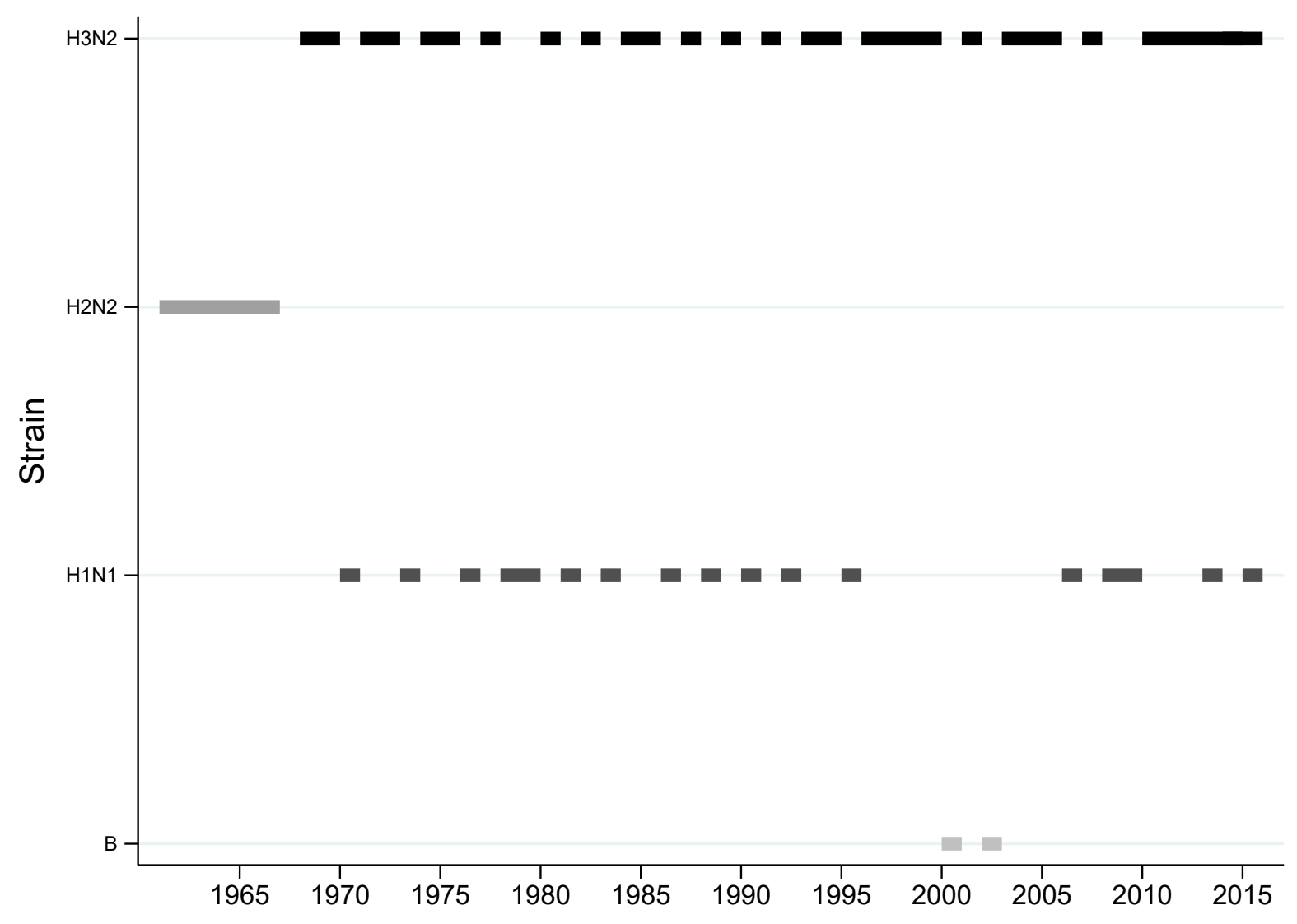

Figure A3: Most Prevalent Influenza Strain by Flu Year 